Federal Reserve Bank of Minneapolis

Research Department Staff Report 407

Revised March 2009

\title{
APPENDICES: Technology Capital and the U.S. Current Account*
}

\author{
Ellen R. McGrattan \\ Federal Reserve Bank of Minneapolis \\ and University of Minnesota \\ Edward C. Prescott \\ Arizona State University \\ and Federal Reserve Bank of Minneapolis
}

\begin{abstract}
Appendix A provides firm-level and industry-level evidence that is consistent with several key features of our model, including the predictions that rates of return increase with a firm's intangible investments and foreign affiliate rates of return increase with age and with their parents' R\&D intensity. Appendix B provides details for the computation of our model's equilibrium paths, the construction of model national and international accounts, and the sensitivity of our main findings to alternative parameterizations of the model. We demonstrate that the main finding of our paper-namely, that the mismeasurement of capital accounts for roughly 60 percent of the gap in FDI returns - is robust to alternative choices of income shares, depreciation rates, and tax rates, assuming the same procedure is followed in setting exogenous parameters governing the model's current account. Appendix $\mathrm{C}$ demonstrates that adding technology capital and locations to an otherwise standard twocountry general equilibrium model has a large impact on the predicted behavior of labor productivity and net exports.
\end{abstract}

*The paper, data, and codes are available at our website http://www.minneapolisfed.org/ research/sr/sr406.html. The views expressed herein are those of the authors and not necessarily those of the Federal Reserve Bank of Minneapolis or the Federal Reserve System. 


\section{Table of Contents}

A. Firm- and Industry-Level Evidence on Rates of Return . . . . . . . . . . . 1

A.1. Rates of Return Increase with Intangible Expenditures . . . . . . . . 1

A.2. Rates of Return of Foreign Affiliates Increase with R\&D of Parents . . . 4

A.3. Rates of Return of Foreign Affiliates Increase with Age . . . . . . . . 6

A.3.1. BEA Studies of Multinational Companies . . . . . . . . . . . 6

A.3.1.1. USDIA Survey . . . . . . . . . . . . . . . . . . . . 7

A.3.1.2. FDIUS Survey . . . . . . . . . . . . . . . . . . . . 11

A.3.2. IRS Studies of U.S. Multinationals . . . . . . . . . . . . . . 12

A.3.2.1. 1982 Tax Returns . . . . . . . . . . . . . . . . . . . 12

A.3.2.2. 1988 Tax Returns . . . . . . . . . . . . . . . . . . . 14

A.3.3. BEA and IRS Statistics, 1982-2006 . . . . . . . . . . . . . . 15

B. Computation, BEA Accounts, and Sensitivity . . . . . . . . . . . . . . . 19

B.1. Introduction . . . . . . . . . . . . . . . . . . . . . 19

B.2. Computation of Equilibrium Paths . . . . . . . . . . . . . . . . . 19

B.2.1. Multinational Problem . . . . . . . . . . . . . . . . . . . 19

B.2.2. Household Problem . . . . . . . . . . . . . . . . . . . . . 21

B.2.3. Resource Constraint . . . . . . . . . . . . . . . . . . . . . 22

B.2.4. Detrended First-Order Conditions . . . . . . . . . . . . . . . 22

B.2.5. Equilibrium Paths . . . . . . . . . . . . . . . . . . . . . 23

B.2.6. Steady State . . . . . . . . . . . . . . . . . . . . . . . . 25

B.2.7. International Equity Values . . . . . . . . . . . . . . . . . 26

B.3. BEA Accounts . . . . . . . . . . . . . . . . . . . . . . . . . . 27

B.4. Sensitivity of Main Results . . . . . . . . . . . . . . . . . . . . 31

C. The Impact of Technology Capital on Productivity and Net Exports . . . . . 41 
C.1. Introduction . . . . . . . . . . . . . . . . . . . . . . . . . . . 41

C.2. Stripped-Down Model . . . . . . . . . . . . . . . . . . . . . . . 42

C.3. Relative Labor Productivities . . . . . . . . . . . . . . . . . . . 44

C.4. Net Exports . . . . . . . . . . . . . . . . . . . . . . . . . . . 49

C.4.1. Steady State Results . . . . . . . . . . . . . . . . . . . . 49

C.4.2. Transition Results . . . . . . . . . . . . . . . . . . . . . 57 


\section{Appendix A.}

\section{Firm- and Industry-Level Evidence on Rates of Return}

Our theory predicts three patterns involving accounting rates of return:

1. Accounting rates of return increase with $R \& D$ and advertising intensities;

2. Accounting rates of return of foreign affiliates increase with parents' R\&D intensity;

3. Accounting rates of return of foreign affiliates increase with age.

In this appendix, we present strong microeconomic evidence supporting these predictions. ${ }^{1}$

\section{A.1. Rates of Return Increase with Intangible Expenditures}

In this section, we provide firm-level and industry-level evidence that accounting rates of return increase with expenditures on $R \& D$ and advertising. This is of interest because our theory predicts that accounting profits are higher than true profits if firms invest in intangible assets. Because these investments are expensed, measured income includes a return on past intangible capital investments, but measured capital excludes the R\&D capital and brand equity. This implies that measured rates of return should increase with R\&D and advertising stocks.

Early studies focused on advertising only. Ali Shah and Akbar (2008) survey the literature relating advertising intensity and profitability back to the 1960s. An important early paper by Comanor and Wilson (1967) found a significantly positive relation across firms between rates of return and advertising intensities for 41 consumer goods industries. The authors attributed this relation to the existence of market power and concluded that

1 All rates of return discussed in this appendix are based on accounting data of U.S. corporations. Adjustments have not been made to convert book values to market values or historical costs to current costs. This is typically done by the Bureau of Economic Analysis (BEA) once firm-level data have been aggregated. 
advertising played a critical role in creating barriers to entry. ${ }^{2}$ Comanor and Wilson (1967) followed standard accounting practice and treated advertising as an expense rather than an investment; they did not correct profit rates by capitalizing advertising expenditures.

Correcting profit rates to appropriately count advertising as an investment led Bloch (1974), Ayanian (1975), and Demsetz (1979) to the opposite conclusion: the strong positive relationship between profit rates and advertising is due to expensing not to market power. Bloch (1974) analyzed 40 firms over the period 1950-1953 with data from Printer's Ink. Ayanian (1975) analyzed 39 firms over the period 1959-1968 with data from Advertising Age. In a follow-up study, Demsetz (1979) noted that "to demonstrate that an accounting artifact is at work is not sufficient to demonstrate an absence of barriers to entry." He addressed the issues separately using IRS data for the period 1958-1967 and found that (1) the correlation between advertising intensity and profit rates was due to accounting practices, and (2) advertising did not create a barrier to entry.

Grabowski and Mueller (1978) reconsider the question of why rates of return are increasing with intangible investments by including both $R \& D$ and advertising before adjusting rates of return. They used a sample of 86 firms primarily in producer goods industries over the period 1959-1966. In Figure A.1, we display the difference in the average rates of return by industry: the rate of return when intangibles are expensed less the rate of return when intangibles are capitalized. The 86 firms were grouped into nine industry categories. There are two miscellaneous categories, denoted progressive and nonprogressive. The classification of progressive and nonprogressive depends on whether a firm's R\&D capital to total capital was above or below 10 percent.

As Figure A.1 indicates, capitalizing intangible investments implies a large adjustment

2 See also the Federal Trade Commission (1972) complaint against the four largest U.S. manufacturers of ready-to-eat cereals. The FTC charged that "these practices of proliferating brands, differentiating similar products and promoting trademarks through intensive advertising result in high barriers to entry in the RTE cereal market. . . . Respondents have obtained profits and returns substantially in excess of those that they would have obtained in a competitively structured market." 
Figure A.1. Rate of Return if R\&D and Advertising are Capitalized

Less Rate if Expensed, by Size of R\&D and Advertising Capital

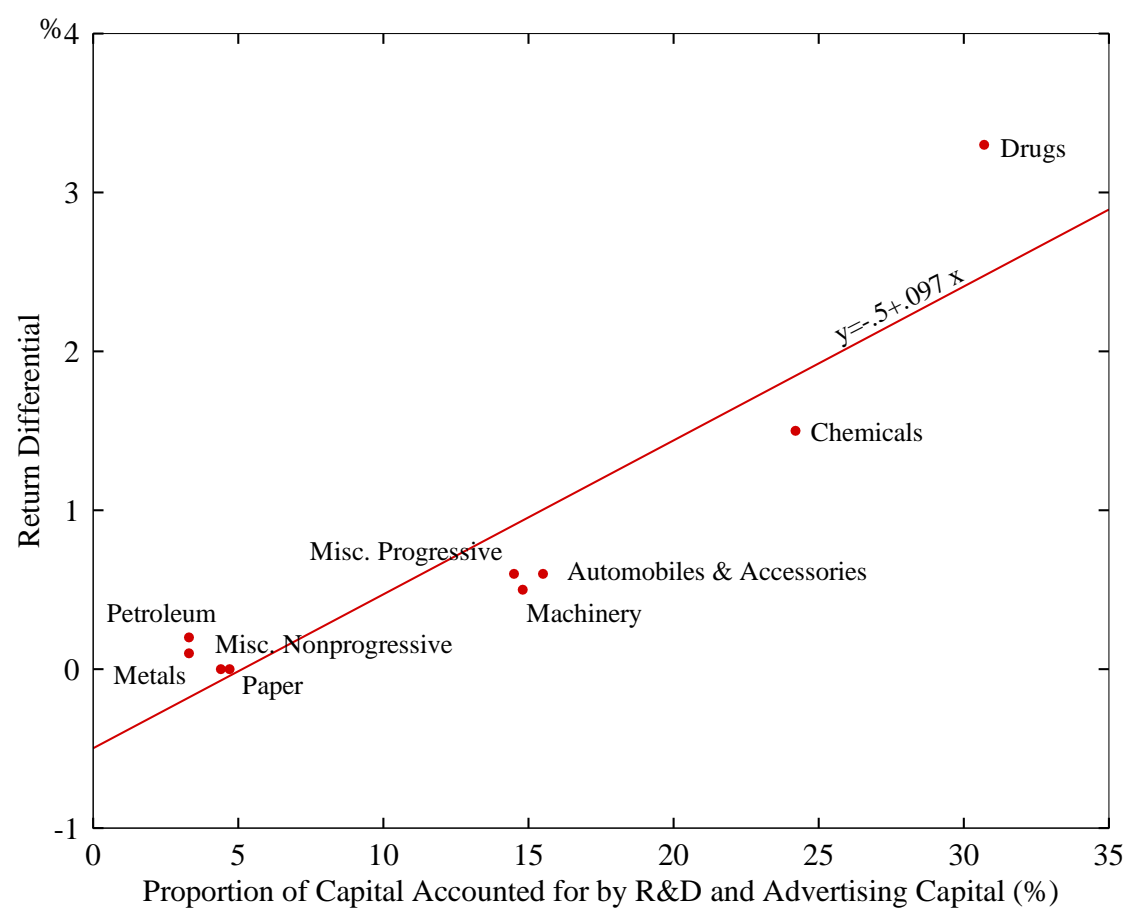

Source: Grabowski and Mueller (1978)

in rates of return for intangible-intensive industries. If we regress the return differential on the proportion of capital accounted for by R\&D and advertising capital, we find the slope is 0.097 with a standard error of 0.017. (The regression line is plotted in Figure A.1 along with the industry averages.) Drug companies, for example, have an accounting rate of return of 14.1 percent and an adjusted rate of return of 10.8 percent. Grabowski and Mueller (1978) find that the overall sample variance for the adjusted rate of return is 54 percent of the variance of the unadjusted rate of return.

To test the hypothesis that the remaining variation in returns is due to differences in market power, Grabowski and Mueller (1978) regress the adjusted rates of return on a fourfirm concentration ratio, which is used to proxy for market power. They find a statistically significant but negative coefficient on the concentration ratio, implying a rejection of the hypothesis that the remaining differences are attributable to market power. They also 
test the impact of risk on firm profitability using a measure of beta from the capital asset

pricing model. This risk measure was found to be insignificant in the regressions that they ran.

Our theory suggests that there are several alternative explanations for the remaining rate of return differences. First, R\&D and advertising are not the only intangible expenditures. Corporations have firm-specific organization capital that is also expensed. Second, multinational corporations require a more complicated rate of return adjustment, since part of their intangible capital — namely technology capital — is used in multiple locations. Third, corporations that are young or multinationals with young affiliates have lower rates of return. This fact necessitates conditioning on the age of the firms.

We turn next to specific evidence on rates of return of foreign affiliates of U.S. corporations. The evidence sheds some light on the role of parents' intangible capital and age for their profitability.

\section{A.2. Rates of Return of Foreign Affiliates Increase with R\&D of Parents}

Our theory says that accounting rates of return of foreign affiliates should increase with expensed investments made by their parents. From the BEA annual survey of U.S. direct investment abroad (USDIA), we have data to construct rates of return for foreign affiliates of U.S. multinationals and data on R\&D expenditures of their parents. We find that there is a strong positive relationship.

In Figure A.2, we plot the rates of return of affiliates versus the ratio of R\&D expenditures to value added of parents. The measured rate of return used for foreign affiliates is the ratio of net income to total assets. For each major industry (using NAIC classification), we average the rates of return over the period 1999 to 2005. The figure includes 
Figure A.2. Rates of Return of Majority-Owned Affiliates

of U.S. Nonbank Parents by R\&D Intensity of Parents

Averages, 1999-2005

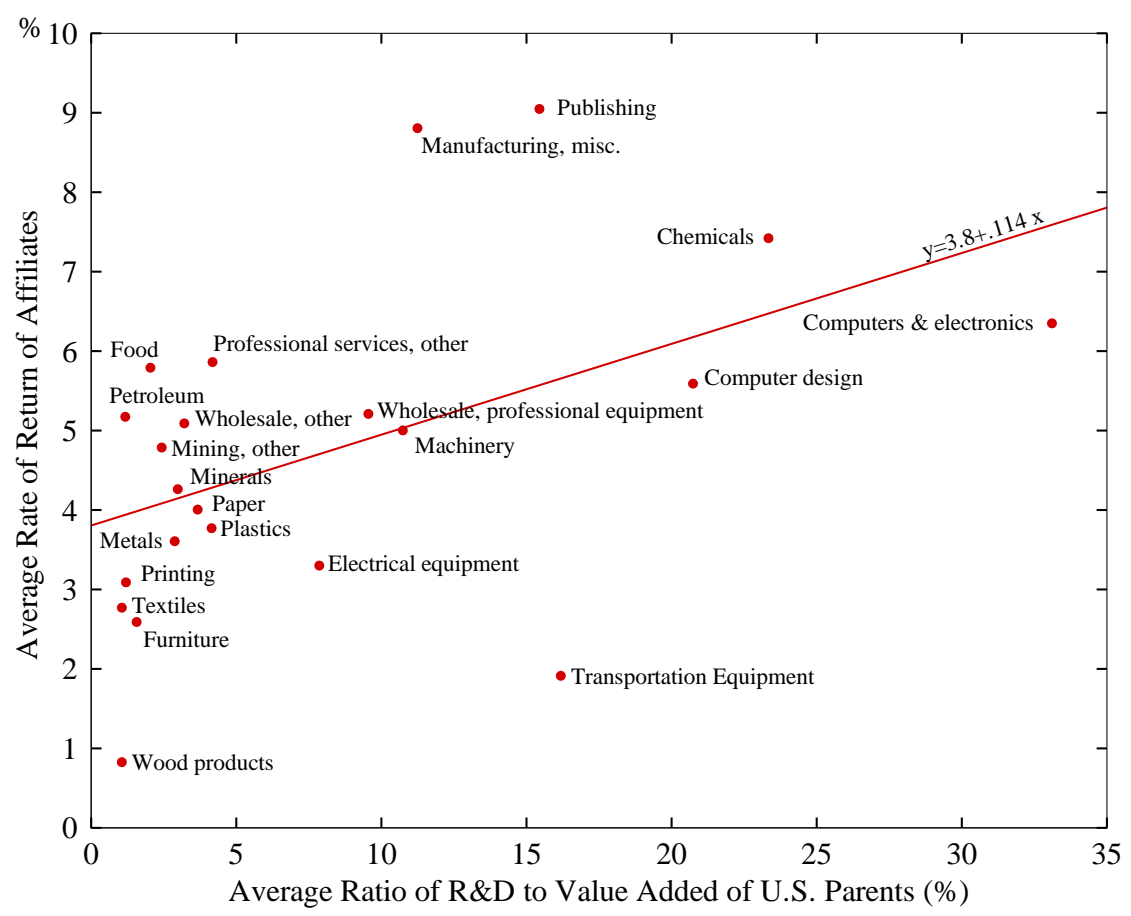

Source: Bureau of Economic Analysis, www.bea.gov

statistics for the 22 major industries that had at least 5 years of data needed to construct the affiliate rates of return, at least 5 years of data needed to construct the ratio of parents' R\&D to value added, and average ratios of $R \& D$ to value added that exceeded 1 percent. ${ }^{3}$

If we regress affiliate rates of return for the 22 industries shown in Figure A.2, then we find a statistically significant positive relationship with a slope of 0.114 and a standard error of 0.046. If we include all industries, even those in which the parents have low R\&D intensities, the number of industries is 34 and the coefficient on the R\&D intensity is 0.142 with a standard error of 0.079 . If we drop three outliers - oil and gas extraction, beverages and tobacco products, and motion picture and sound recording industries - from the full

3 In some cases, data are suppressed for confidentiality reasons. Industries with very low R\&D intensities are not shown so that the graph is readable. Later, we describe how the results change if all industries are included. 
sample, then the coefficient rises to 0.193 with a standard error of $0.069 .{ }^{4}$ If we restrict ourselves to industries with complete data for the period 1999-2005 and any level of R\&D for the parents, we find a coefficient of 0.145 and a standard error of 0.055 .

The results are also robust to the set of affiliates and the industry categorization. The affiliates' rates of return shown in Figure A.2 are based on data of majority-owned affiliates that are categorized according to their own industry. Results are not significantly altered if we use all affiliates or categorize affiliates by their parents' primary industry.

In summary, we find a strong positive relationship between affiliates' rates of return and parents' R\&D expenditures.

\section{A.3. Rates of Return of Foreign Affiliates Increase with Age}

Our theory says that accounting rates of return of foreign affiliates should increase with the age of the affiliate, starting out below rates of return for the parents and eventually rising to levels above the rates of return for the parents. In this section, we discuss studies done by the BEA and the Internal Revenue Service (IRS) on rates of return of foreign affiliates of multinational companies in different age categories. ${ }^{5}$ These studies show that rates of return generally increase with an affiliate's age. When compared to rates of return for parents, we find that affiliates' rates of return start lower and rise above the rates of their parents. On average, we find that affiliates appear more profitable than their parents. This is what we would expect if parents expense most of the investment in technology capital.

\section{A.3.1. BEA Studies of Multinational Companies}

4 One motivation for dropping these outliers is that they are themselves intangible-intensive industries. Oil and gas industries have large drilling expenses, and the others have large advertising expenses.

5 The BEA's definition of age is the number of years the U.S. parent has owned the affiliate, and the IRS's definition of age is the number of years since the affiliate's incorporation. 
The BEA conducts surveys of U.S. multinational companies and their affiliates and U.S. affiliates of foreign multinationals. Three sets of data are collected: (1) balance of payments and direct investment position data, (2) financial and operating data, and (3) establishment and acquisition data. In addition to using the data for compiling the international accounts, the BEA and researchers using the BEA data frequently conduct studies to assess the impact of multinational activity on the U.S. and foreign economies. In this section, we focus on two such studies that consider the relationship of rates of return and age of affiliates.

\section{A.3.1.1. USDIA Survey}

In the August 1978 issue of the Survey of Current Business, Lupo, Gilbert, and Liliestedt report findings of their investigation of the relationship between age and rate of return of 4,507 foreign manufacturing affiliates of U.S. manufacturing parent companies. They summarized their findings as follows: "Information from the BEA 1966 benchmark survey of U.S. direct investment abroad shows that the rate of return of foreign affiliates of U.S. parent companies increases with age" (p. 60). In this section, we describe the information available to the BEA from their benchmark survey, the econometric tests run by the three authors of the study, their main findings, and some robustness tests that they conducted.

BEA benchmark surveys of U.S. direct investment abroad (USDIA) provide income statement data and balance sheet data for foreign affiliates of U.S. corporations and U.S. parents as they are recorded on their books. To construct rates of return, Lupo et al. (1978) divide before-tax net income by total assets net of depreciation.

For the 1966 survey, ten age categories are available for U.S. affiliates. Age is defined as the number of years that the U.S. parent has owned the affiliate. For their study, Lupo et al. condensed these age categories into four: under 4 years, 4 to 6 years, 7 to 9 years, and 10 years and older. They also split the sample by industry and area to make sure 
Figure A.3. Rates of Return of Foreign Manufacturing

Affiliates of U.S. Manufacturing Parents,

By Age of Affiliate

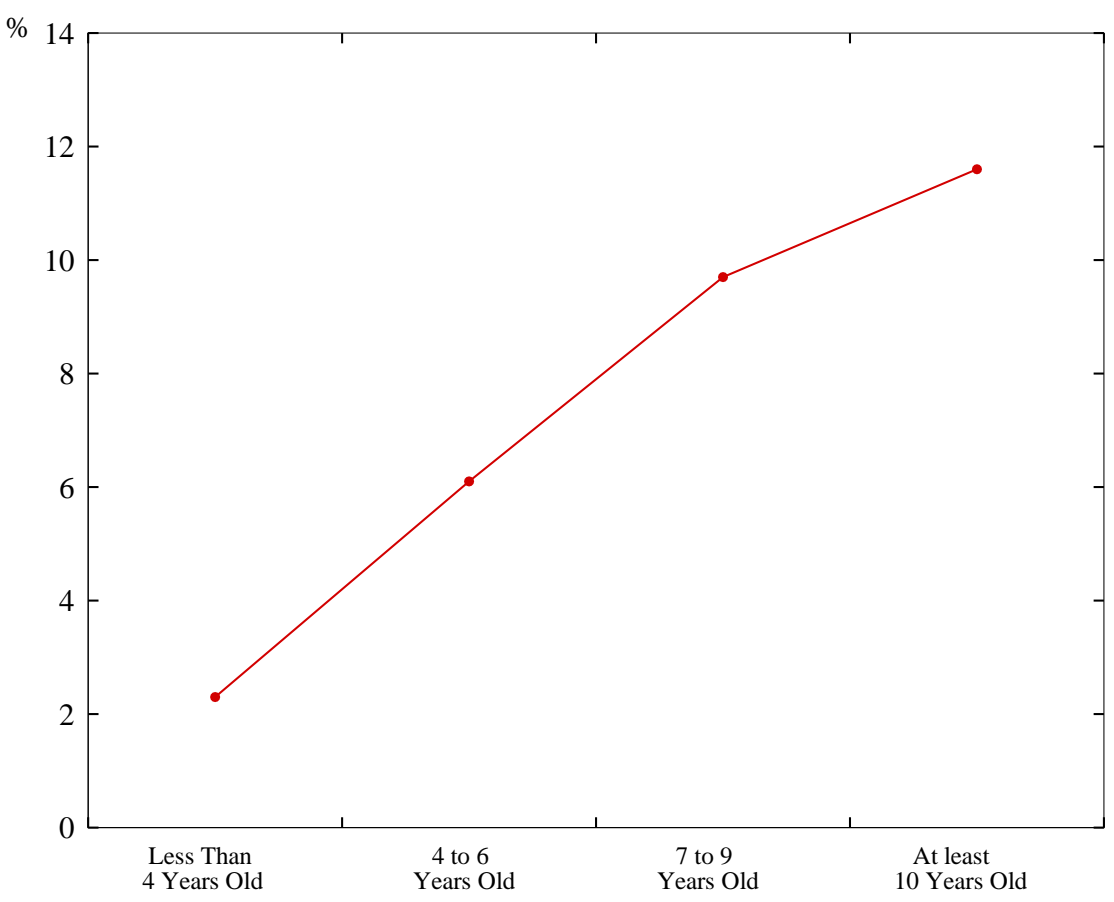

Source: Lupo, Gilbert, and Liliestedt (1978)

that the relationship was, in their words, "genuine" and not a result of where or what the affiliates were producing.

Figure A.3 shows the rates of return for the total sample by age. The range of returns is 2.3 percent for affiliates less than 4 years old and 11.6 percent for those at least 10 years old. Figures A.4 and A.5 show the decomposition by industry and by area, respectively.

With a few exceptions, the rates of return are monotonically increasing with age. Lupo et al. (1978) note that the lack of variation in the transportation equipment is due to a relatively young European affiliate owning several old affiliates. They attribute the nonmonotonicity in metals to some age groups in this industry having only a few affiliates 
that dominate the calculations. They attribute the high returns of young Canadian affiliates to the operations of automotive affiliates, which were closely integrated with their U.S. parents.

Lupo et al. (1978) check the robustness of their results in several ways. First, they recalculated returns with after-tax net income rather than before-tax net income. The main conclusions are not altered. For example, they find that the rate of return increases from 0.1 percent for affiliates less than 4 years old to 6.6 percent for affiliates at least 10 years old.

A second check shows that the relationship between age and affiliate's rate of return is not due to secular inflation. It is possible that inflation could bias Lupo et al.'s results given that values on the accounts are book values. Older assets are understated if secular inflation is high. This understatement implies that older affiliates would have higher returns than younger affiliates simply because inflation is positive (and not necessarily because of large expensed investments incurred with setting up new operations).

To check this hypothesis, the authors decomposed the rate of return as follows:

$$
\frac{N I B T}{A}=\frac{I B D T}{S} \times \frac{N I B T}{I B D T} \times \frac{S}{C A} \times \frac{C A}{A}
$$

where $N I B T$ is net income before tax, $A$ is assets, $I B D T$ is income before depreciation and tax, $S$ is sales, and $C A$ is current assets. The second and fourth terms in (A.3.1) are sensitive to inflation because asset values are the book values and depreciation values depend on when the assets were acquired. The first and third terms are not sensitive.

Consider the rates of return in Figure A.3, which rise from 2.3 percent for the younger affiliates to 11.6 percent for the older affiliates. The product of the inflation-insensitive components $(N I B T / I B D T \times C A / A)$ rises from 10.7 to 30.6 , which is roughly a factor of 3. The product of the inflation-sensitive components $(I B D T / C A)$ rises from 21.7 to 37.8, which is a factor of 1.7. This tells us that factors other than inflation are driving the 
Figure A.4. Rates of Return of Foreign Manufacturing

Affiliates of U.S. Manufacturing Parents,

By Age And Industry of Affiliate

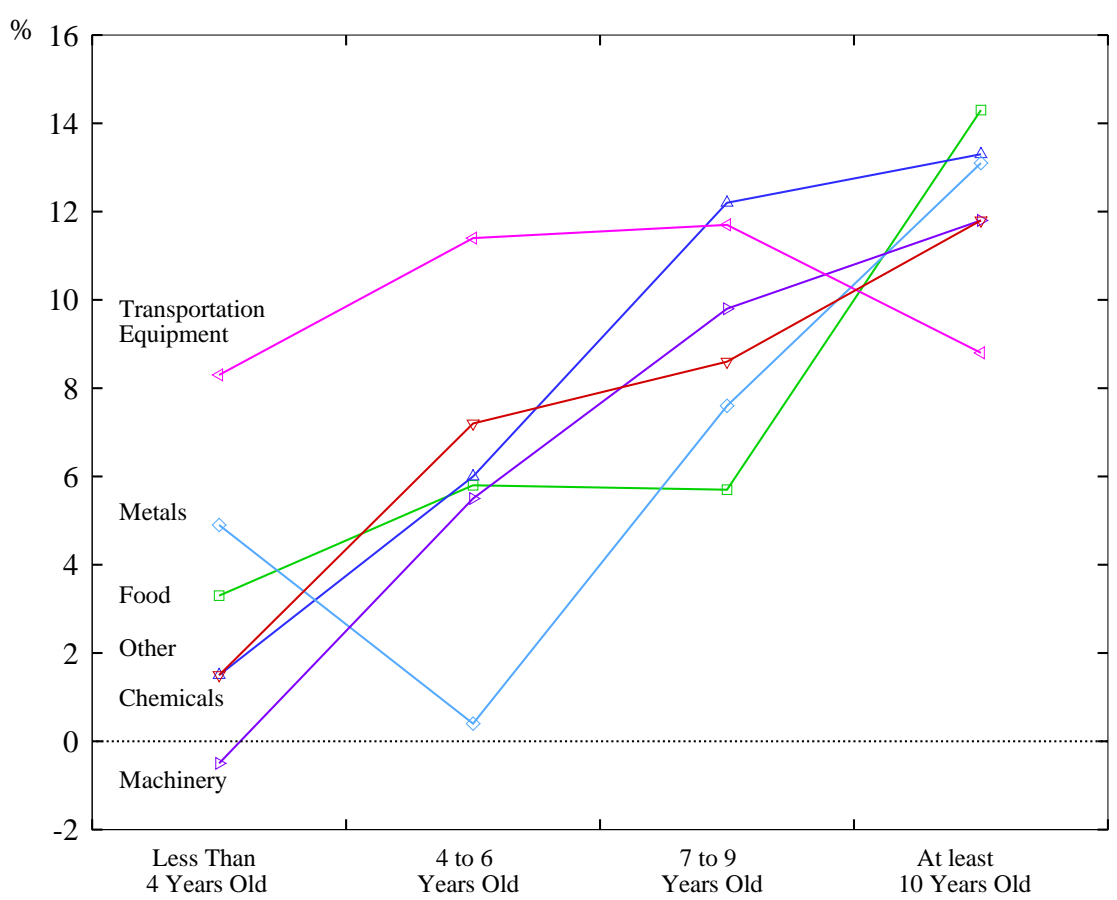

Figure A.5. Rates of Return of Foreign Manufacturing Affiliates of U.S. Manufacturing Parents, By Age And Area of Affiliate

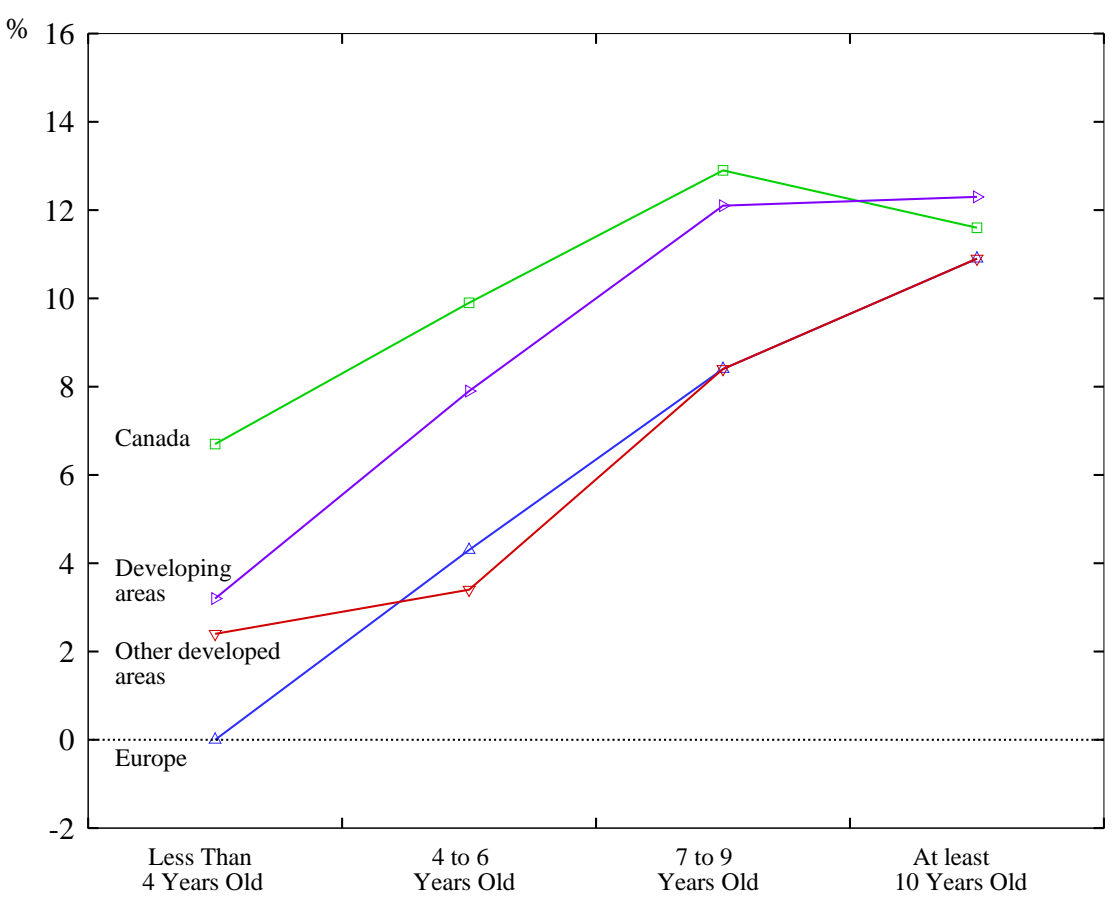

Source: Lupo, Gilbert, and Liliestedt (1978) 
main results. Furthermore, most of the variation in the inflation-sensitive factors is due to a low value of net income NIBT for young European affiliates. Lupo et al. (1978) view their income figure as an aberration and their estimate of the contribution of inflation to the positive relationship between age and rate of return as an upper bound. Thus, they conclude that rising inflation is not a key factor behind the relationship between age and rate of return of foreign affiliates.

In one final check of their results, Lupo et al. (1978) considered affiliates' size and age separately to see if age effect was merely an artifact of size. They find that age and size are correlated, and conditioning on size, still find a positive relationship between age and rates of return of foreign affiliates. In our theory, size and age would be correlated, since new affiliates are building up both their tangible capital and their intangible capital as foreign countries open up.

\section{A.3.1.2. FDIUS Survey}

In the March 2000 issue of the Survey of Current Business, Mataloni reports on the relationship between the return on assets gap and the newness of foreign ownership for 7,906 foreign-owned nonfinancial companies operating in the United States in 1989 and 10,223 foreign-owned nonfinancial companies operating in the United States in $1996 .{ }^{6}$ The return on assets (ROA) is the rate of return measure used in the study and is defined to be the ratio of profits from current production plus interest to the end-of-year total assets. The ROA gap is defined to be the return on assets for a foreign-owned company less the return on assets for all U.S.-owned companies in the same industry. The newness measure he uses is the new-asset ratio, which is defined to be the ratio of the assets acquired or established in the preceding two years to the current-year assets.

In Table A.1, we reproduce the results of Mataloni (2000). The table shows that

${ }^{6}$ See also some related studies cited in Mataloni (2000). 
Table A.1. Differences in Rates of Return of Foreign-Owned U.S. Nonfinancial Companies and All U.S.-Owned Nonfinancial Companies, By NeW-Asset Ratio

\begin{tabular}{c|c|c}
\hline Year & $\begin{array}{c}\text { Low new- } \\
\text { asset ratio }\end{array}$ & $\begin{array}{c}\text { High new- } \\
\text { asset ratio }\end{array}$ \\
\hline 1989 & -1.7 & -3.0 \\
1996 & -2.3 & -3.2 \\
\hline
\end{tabular}

Note: A new asset ratio less than 25 percent is categorized as "low" and above that as "high."

companies in 1989 with a high new-asset ratio had a rate of return gap that is almost twice as large as the companies with a low ratio, -3.0 versus -1.7 . The difference is not as large in 1996, but in both years the differences in the gaps were found to be statistically significant.

\section{A.3.2. IRS Studies of U.S. Multinationals}

The IRS biannually publishes statistics for foreign affiliates called controlled foreign corporations whose voting stock is more than 50 percent owned by a U.S. corporation (or other person). Until very recently, the statistics were reported only for large U.S. corporations with total assets over a certain size. For the 1982 and 1988 tax returns, the IRS published further detailed statistics for foreign affiliates by year of incorporation. ${ }^{7}$ In this section, we report on some of these statistics and show that they confirm the findings of the BEA studies.

\section{A.3.2.1. 1982 Tax Returns}

Table A.2 summarizes statistics from 1982 tax returns for three categories of corporations:

7 For complete details, see Simenauer (1986) and Latzy and Miller (1992). 


\begin{tabular}{|c|c|c|c|c|}
\hline \multirow{3}{*}{$\begin{array}{l}\text { Statistics from } \\
1982 \text { Tax Returns }{ }^{a} \\
\text { Rate of Return by Industry of: }{ }^{b}\end{array}$} & \multirow{3}{*}{$\begin{array}{c}\text { Large U.S. } \\
\text { Corporations } \\
\text { Parent } \\
\end{array}$} & \multicolumn{3}{|c|}{ Affiliates of Large U.S. Corporations } \\
\hline & & \multicolumn{2}{|c|}{ Total } & \multirow{2}{*}{$\begin{array}{c}\text { Incorporated } \\
\text { in } 1982 \\
\text { Affiliate } \\
\end{array}$} \\
\hline & & Parent & Affiliate & \\
\hline All industries & 2.0 & 6.6 & 6.6 & 1.5 \\
\hline Mining & 2.7 & 11.0 & 18.1 & -4.2 \\
\hline Construction $^{3}$ & 3.8 & 16.1 & 10.8 & NA \\
\hline Manufacturing & 3.7 & 7.6 & 8.6 & 2.9 \\
\hline Transportation \& public utilities & 2.3 & 6.6 & 2.6 & 2.1 \\
\hline Wholesale and retail trade & 2.5 & 5.8 & 4.6 & 0.9 \\
\hline Finance, insurance \& real estate & 0.2 & 2.4 & 3.5 & 1.7 \\
\hline Services & 3.7 & 6.6 & 9.6 & 0.7 \\
\hline $\begin{array}{l}\text { Number of Corporations } \\
\text { Total Assets }\end{array}$ & $\begin{array}{c}1,034 \\
\$ 4,198,723\end{array}$ & \multicolumn{2}{|c|}{$\begin{array}{c}26,993 \\
\$ 557,207 \\
\end{array}$} & $\begin{array}{c}950 \\
\$ 12,417 \\
\end{array}$ \\
\hline
\end{tabular}

Note: Statistics are derived from tax returns of U.S. corporations with total assets of $\$ 250$ million or more, accounting periods ended July 1982 through June 1983, and attached Form(s) 2952 (Information Return with Respect to Controlled Foreign Corporations) or Form(s) 5471 (Information Return with Respect to a Foreign Corporation). Data reported are for the entire universe of corporations in this group, so there is no sampling variability.

$a$ The affiliate rate of return is defined as the ratio of earnings and profits before taxes to total assets. The U.S. parent rate of return is defined as the ratio of net income before tax to total assets. Columns marked "Parent" report statistics using the industry of the U.S. parent. Columns marked "Affiliate" report statistics using the industry of the foreign affiliates.

${ }^{b} \mathrm{NA}=$ not available; earnings for this category were reported as less than $\$ 500,000$.

(1) large U.S. parents - where "large" refers to corporations with $\$ 250$ million or more in assets, (2) foreign affiliates of large U.S. parents, and (3) recently incorporated foreign affiliates of large U.S. parents. We report on rates of return by industry, total number of corporations, and total assets for each group. Rates of return are computed in the same way by the IRS as by the BEA. The rate of return for affiliates is defined as the ratio of earnings and profits before taxes to total assets. The rate of return for parents is defined as the ratio of net income before taxes to total assets. Since the primary activity of affiliates and parents may differ, we report rates of return by industry of the U.S. parent and by industry of the foreign affiliate. 
Two important patterns emerge from these statistics. First, we find that affiliates are more profitable than their parents on average. This finding is consistent with our theory that assumes parents expense technology capital at home and affiliates use it in production abroad. Second, we find that recently incorporated affiliates are less profitable than their parents and less profitable than affiliates incorporated in the past. This finding is consistent with our theory that assumes affiliates make large initial plant-specific intangible investments abroad. These patterns hold for all major industries. Furthermore, the fact that returns are higher for older affiliates supports the BEA studies of Lupo et al. (1978) and Mataloni (2000) showing a positive relationship between rates of return and age.

\section{A.3.2.2. 1988 Tax Returns}

In 1988, the IRS provided more details by date of incorporation for the largest 7,500 foreign affiliates of large corporations. Corporations were categorized as large in 1988 if they had total assets of $\$ 500$ million or more.

In Figure A.6, we graph rates of return for affiliates in all industries and in manufacturing as a function of their year of incorporation. The rates or return are defined to be the ratio of current earnings and profits (less deficit) before taxes to total assets. To make the graph similar to that in Lupo et al. (1978), we aggregate corporations incorporated before 1980 and show these results along with results for three early age categories. We do this because most of the variation in rates of return is observed in the first 10 years.

For large foreign affiliates in manufacturing, the range of rates of return is a little over 5 percent to 15 percent. This is a little higher than Lupo et al.'s (1978) estimates, which were in the range of 2 to 12 percent. The difference is likely attributable to the fact that the BEA survey includes large and small affiliates whereas the IRS includes only large affiliates. 
Figure A.6. Rates of Return of 7,500 Largest Foreign Affiliates

of U.S. Parents with Total Assets of $\$ 500$ Million or More, By Year of Incorporation of AfFiliate

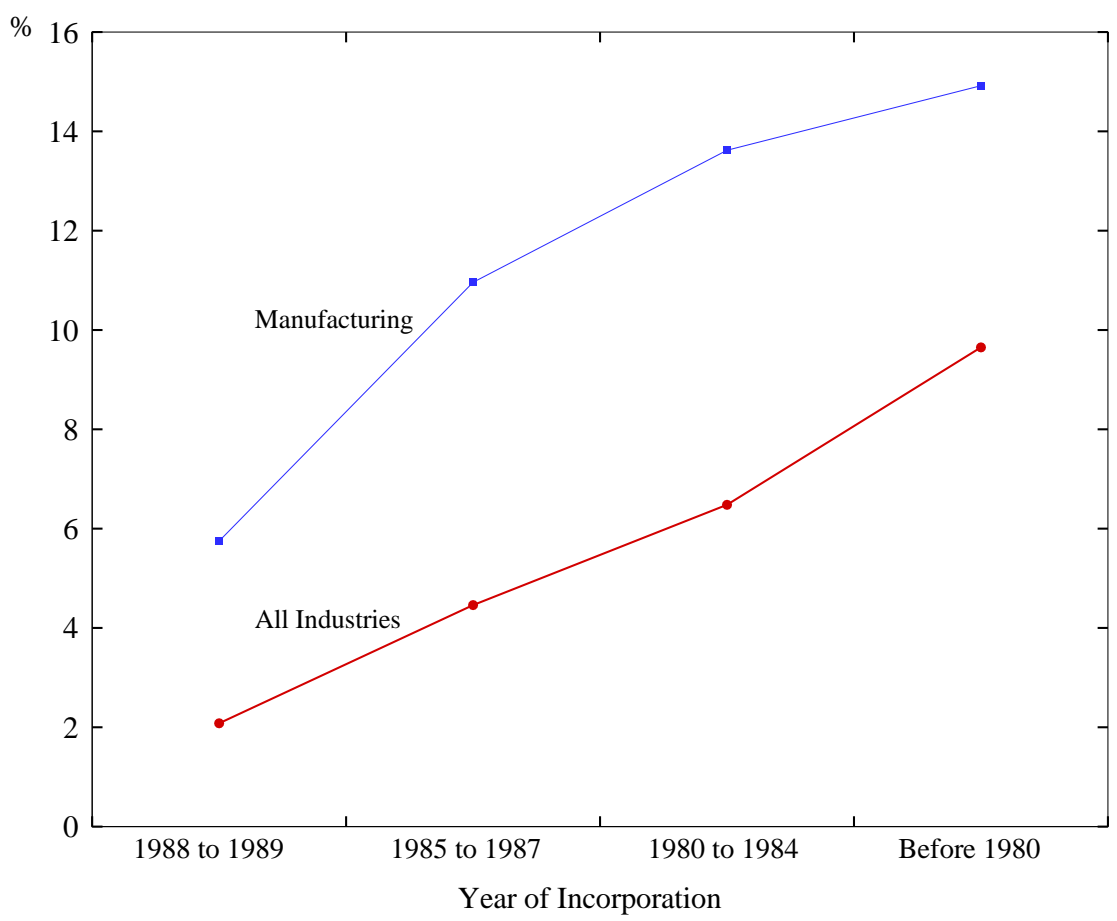

Source: Latzy and Miller (1992)

Another noteworthy feature of the results in Figure A.6 is the discrepancy in rates of return between manufacturing and all industries. Manufacturing industries are more R\&D intensive and therefore should have higher accounting rates of return. For the recently incorporated, the difference in average rates of return is close to 4 percent. For the older affiliates, incorporated before 1980, the difference in average rates of return is about 5 percent.

\section{A.3.3. BEA and IRS Statistics, 1982-2006}

Thus far, we have considered cross-sectional and time-averaged firm- and industry-level evidence on affiliates' rates of return. We showed that rates of return of young affiliates start out below rates of return of their parents and eventually exceed them. Using data in 
Figure A.7. Rates of Return of Foreign Affiliates Less Rates

of Return of U.S. Parents Based on Tax Returns of Large

Multinationals and Surveys of All Multinationals

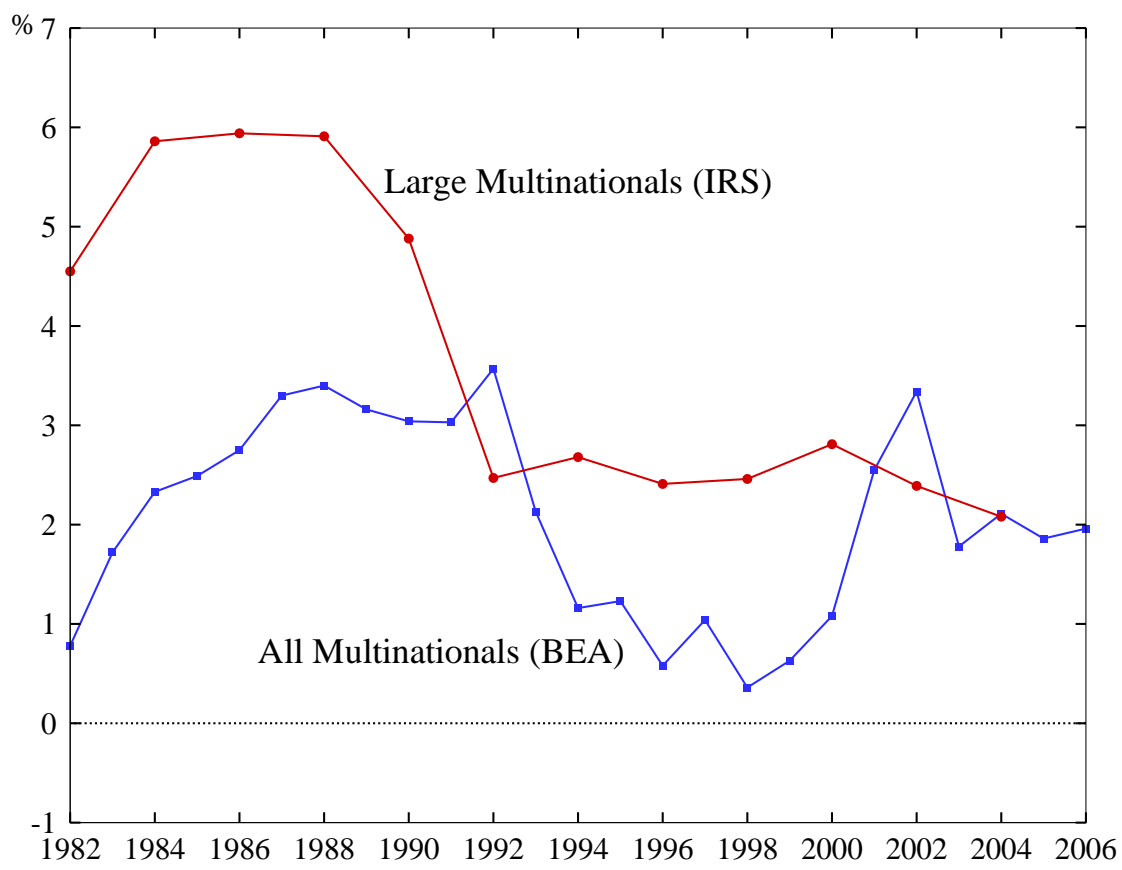

Source: Statistics of Income bulletins and BEA USDIA surveys

1982, we showed that affiliate rates of return were on average higher than those of their parents. The fact that rates of return eventually rise above that of the parents is consistent with the assumption that technology capital is expensed at home and used abroad, implying a rate of return differential due to accounting practices. Here, we investigate this implication using all available data from BEA USDIA surveys and IRS corporate tax returns.

In Figure A.7, we plot the rate of return differential between majority-owned affiliates and U.S. parents based on the biannual IRS statistics and the annual BEA USDIA surveys. $^{8}$ The main difference in the two are the coverage: the IRS reports statistics for

8 Prior to 1988, the IRS published separate statistics for large corporations and for large corporations that filed Forms 2952 or 5471 with information specific to their controlled foreign corporations. Therefore, starting in 1988, we used statistics for all large corporations when computing the rate of return for U.S. parents. In 1986, large corporations that filed 2952 or 5471 had a rate of return of 
large multinationals, and the BEA reports statistics for all multinationals. Despite the difference in coverage, both plots in Figure A.7 show that the affiliates' accounting rates of return exceeded that of the parents in every year of the sample. For large multinationals, the average return differential based on tax returns is 3.8 percent. For all multinationals in the BEA USDIA survey, the average return differential is 2.1 percent.

To summarize, we have shown that there is an abundance of firm-level and industrylevel evidence supporting three key implications of our theory involving accounting rates of return: rates of return increase with intangible expenditures, affiliates' rates of return increase with the parents' R\&D intensity, and affiliates' rates of return increase as they age.

1.7 percent, all large firms had a rate of return of 1.77 percent, and affiliates of large corporations had a rate of return of 7.64 percent. 


\section{References}

Ali Shah, Syed Zulfiqar, and Saeed Akbar, 2008, "Value Relevance of Advertising Expenditure: A Review of the Literature," International Journal of Management Reviews, 10(4): 301-325.

Ayanian, Robert, 1975, "Advertising and Rate of Return," Journal of Law and Economics, 18(2): 479-506.

Bloch, Harry, 1974, "Advertising and Profitability: A Reappraisal," Journal of Political Economy, 82(2): 267-286.

Comanor, William S., and Thomas A. Wilson, 1967, "Advertising Market Structure and Performance," Review of Economics and Statistics, 49(4): 423-440.

Demsetz, Harold, 1979, "Accounting for Advertising as a Barrier to Entry," Journal of Business, 52(3): 345-360.

Federal Trade Commission, 1972, F.T.C. versus Kellogg Co., Docket No. 8883, April 26.

Grabowski, Henry G., and Dennis C. Mueller, 1978, "Industrial Research and Development, Intangible Capital Stocks, and Firm Profit Rates," Bell Journal of Economics, $9(2): 328-343$.

Latzy, John, and Randy Miller, 1992, "Controlled Foreign Corporations, 1988," Statistics of Income Bulletin, 12(2): 60-87.

Lupo, L. A., Arnold Gilbert, and Michael Liliestedt, 1978, "The Relationship Between Age and Rate of Return of Foreign Manufacturing Affiliates of U.S. Manufacturing Parent Companies," Survey of Current Business, 58(8): 60-66.

Mataloni, Raymond J., 2000, "An Examination of the Low Rates of Return of ForeignOwned U.S. Companies," Survey of Current Business, 80(3): 55-73.

Simenauer, Ronald, 1986, "Controlled Foreign Corporations, 1982: An Industry Focus," Statistics of Income Bulletin, 6(1): 63-86. 


\section{Appendix B.}

\section{Computation, BEA Accounts, and Sensitivity}

\section{B.1. Introduction}

In this appendix, we provide details for computing equilibrium paths of our model economy and constructing model accounts comparable to the national and international accounts of the BEA We also conduct sensitivity analysis with the model. We demonstrate that the main finding of our paper-namely, that the mismeasurement of capital accounts for roughly 60 percent of the gap in foreign direct investment (FDI) returns - is robust to alternative choices of income shares, depreciation rates, and tax rates, assuming the same procedure is followed in setting exogenous parameters governing the model's current account.

\section{B.2. Computation of Equilibrium Paths}

We let $i$ index countries and $j$ index multinational companies. Assume that $j \in J^{i}$ are incorporated in country $i$ (where the $J^{i}$ sets are mutually exclusive). ${ }^{9}$

\section{B.2.1. Multinational Problem}

Multinational $j$ solves

$$
\max \sum_{t} p_{t}\left(1-\tau_{d t}\right) D_{t}^{j}
$$

where

$$
D_{t}^{j}=\sum_{i}\left\{\left(1-\tau_{p, i t}\right)\left(Y_{i t}^{j}-W_{i t} L_{i t}^{j}-\delta_{T} K_{T, i t}^{j}-X_{I, i t}^{j}-\chi_{i}^{j} X_{M, t}^{j}\right)-\left(K_{T, i, t+1}^{j}-K_{T, i t}^{j}\right)\right\}
$$

9 Without loss of generality, we will work with a representative multinational where the index $j$ denotes the country of incorporation. 
and $\sum_{j} \chi_{i}^{j}=1$,

$$
\begin{aligned}
K_{T, i, t+1}^{j} & =\left(1-\delta_{T}\right) K_{T, i t}^{j}+X_{T, i t}^{j} \\
K_{I, i, t+1}^{j} & =\left(1-\delta_{I}\right) K_{T, i t}^{j}+X_{I, i t}^{j} \\
M_{t+1}^{j} & =\left(1-\delta_{M}\right) M_{t}^{j}+X_{M, t}^{j} .
\end{aligned}
$$

Outputs are given by

$$
\begin{aligned}
& Y_{i t}^{j}=F\left(N_{i t}, M_{t}^{j}, Z_{i t}^{j} ; A_{i t}^{j}\right)=A_{i t}^{j}\left(N_{i t} M_{t}^{j}\right)^{\phi}\left(Z_{i t}^{j}\right)^{1-\phi} \\
& Z_{i t}^{j}=G\left(K_{T, i t}^{j}, K_{I, i t}^{j}, L_{i t}^{j}\right)=\left(K_{T, i t}^{j}\right)^{\alpha_{T}}\left(K_{I, i t}^{j}\right)^{\alpha_{I}}\left(L_{i t}^{j}\right)^{1-\alpha_{T}-\alpha_{I}},
\end{aligned}
$$

where $F$ and $G$ are the same for all $i$ and $j$.

The first-order conditions for multinational $j$ with respect to $L, K_{T}, K_{I}$, and $M$ are

$$
\begin{aligned}
W_{i t} & =F_{3, i t}^{j} G_{3, i t}^{j} \\
& =(1-\phi)\left(1-\alpha_{T}-\alpha_{I}\right) Y_{i t}^{j} / L_{i t}^{j} \\
\frac{\left(1-\tau_{d t}\right) p_{t}}{\left(1-\tau_{d, t+1}\right) p_{t+1}} & =1+\left(1-\tau_{p, i, t+1}\right)\left(F_{3, i, t+1}^{j} G_{1, i, t+1}^{j}-\delta_{T}\right) \\
& =1+\left(1-\tau_{p, i, t+1}\right)\left((1-\phi) \alpha_{T} Y_{i, t+1}^{j} / K_{T, i, t+1}^{j}-\delta_{T}\right) \\
& \equiv 1+\left(1-\tau_{p, i, t+1}\right)\left(r_{T, i, t+1}^{j}-\delta_{T}\right) \\
\frac{\left(1-\tau_{d t}\right) p_{t}}{\left(1-\tau_{d, t+1}\right) p_{t+1}} & =\frac{\left(1-\tau_{p, i, t+1}\right)}{\left(1-\tau_{p, i t}\right)}\left(F_{3, i, t+1}^{j} G_{2, i, t+1}^{j}+1-\delta_{I}\right) \\
& \equiv \frac{\left(1-\tau_{p, i, t+1}\right)}{\left(1-\tau_{p, i t}\right)}\left((1-\phi) \alpha_{I} Y_{i, t+1}^{j} / K_{I, i, t+1}^{j}+1-\delta_{I}\right) \\
\frac{\left(1-\tau_{p, i t}\right)}{\left(1-\tau_{d t}\right) p_{t}}\left(r_{T, i, t+1}^{j}+1-\delta_{I}\right) & \frac{\sum_{i}\left(1-\tau_{p, i, t+1}\right)\left(F_{2, i, t+1}^{j}+\chi_{i}^{j}\left(1-\delta_{M}\right)\right)}{\sum_{i}\left(1-\tau_{p, i t}\right) \chi_{i}^{j}}
\end{aligned}
$$




$$
\begin{aligned}
& =\frac{\sum_{i}\left(1-\tau_{p, i, t+1}\right)\left(\phi Y_{i, t+1}^{j} / M_{t+1}^{j}+\chi_{i}^{j}\left(1-\delta_{M}\right)\right)}{\sum_{i}\left(1-\tau_{p, i t}\right) \chi_{i}^{j}} \\
& \equiv \frac{\sum_{i}\left(1-\tau_{p, i, t+1}\right)\left(r_{M, i, t+1}^{j}+\chi_{i}^{j}\left(1-\delta_{M}\right)\right)}{\sum_{i}\left(1-\tau_{p, i t}\right) \chi_{i}^{j}} .
\end{aligned}
$$

\section{B.2.2. Household Problem}

Households choose sequences of consumption $C_{i t}$, labor $L_{i t}$, shares in companies from $j$ $S_{i t}^{j}$, and bonds $B_{i t}$ to solve the following problem:

$$
\begin{aligned}
& \max \sum_{t} \beta^{t} U\left(C_{i t} / N_{i t}, L_{i t} / N_{i t}+\bar{L}_{n b, i t} / N_{i t}\right) N_{i t} \\
& \text { subj. to } \sum_{t} p_{t}\left[\left(1+\tau_{c i}\right) C_{i t}+\sum_{j} V_{t}^{j}\left(S_{i, t+1}^{j}-S_{i t}^{j}\right)+B_{i, t+1}-B_{i t}\right] \\
& \leq \sum_{t} p_{t}\left[\left(1-\tau_{l i}\right) W_{i t} L_{i t}+\left(1-\tau_{d t}\right) \sum_{j} S_{i t}^{j} D_{t}^{j}+r_{b t} B_{i t}+\kappa_{i t}\right],
\end{aligned}
$$

where $\bar{L}_{n b, i t}$ is exogenously determined labor in the nonbusiness sector, $\tau_{c i}, \tau_{l i}$, and $\tau_{d t}$ are tax rates on consumption, labor, and company distributions, $V_{t}^{j}$ is the price of a share in $j$, $W_{i t}$ is the wage rate in country $i$, and $r_{b t}$ is the after-tax return on lending/borrowing. We assume that country $i$ has a population of size $N_{i t}=n_{i t}\left(1+\gamma_{N}\right)^{t}$, with common growth rate $\gamma_{N}$ and a country-specific shifter $n_{i t}$. Note that the measure of a country's production locations is proportional to its population. Hence, we use the same notation for both variables and set the constant of proportionality equal to one (without loss of generality).

We have included nonbusiness hours (exogenously) in total hours and will include nonbusiness income less investment in $\kappa_{i}$. The nonbusiness sector is added in order to ensure that the national income and product accounts (NIPA) aggregates are of the right order of magnitude. Because our focus is on returns to capital, we also assume that taxes on consumption and labor are constant over time while technology parameters and tax rates on dividends and profits vary over time. 
If $U(c, l)=\log c+\psi \log (1-l)$, then the first-order conditions with respect to $C_{i}, L_{i}$, $B_{i}$, and $S_{i}$ for the household in country $i$ are

$$
\begin{aligned}
\lambda\left(1+\tau_{c i}\right) p_{t} & =\beta^{t} U_{c, i t}=\beta^{t} N_{i t} / C_{i t} \\
\lambda\left(1-\tau_{l i}\right) W_{i t} p_{t} & =\beta^{t} U_{l, i t}=\psi \beta^{t} /\left(1-L_{i t} / N_{i t}-\bar{L}_{n b, i t} / N_{i t}\right) \\
\frac{p_{t}}{p_{t+1}} & =\left(1+r_{b, t+1}\right) \\
\frac{p_{t}}{p_{t+1}} & =\left(\frac{V_{t+1}^{j}+\left(1-\tau_{d, t+1}\right) D_{t+1}^{j}}{V_{t}^{j}}\right), \quad \forall j,
\end{aligned}
$$

where $\lambda$ is the Lagrange multiplier associated with the household budget constraint.

\section{B.2.3. Resource Constraint}

The worldwide resource constraint is

$$
\sum_{i} C_{i t}+\sum_{i, j}\left[X_{T, i t}^{j}+X_{I, i t}^{j}\right]+\sum_{j} X_{M, t}^{j}+\sum_{i} \bar{X}_{n b, i t}=\sum_{i, j} Y_{i t}^{j}+\sum_{i} \bar{Y}_{n b, i t} .
$$

Here, we have explicitly included (exogenous) nonbusiness investment $\bar{X}_{n b, i}$ and output $\bar{Y}_{n b, i}$.

\section{B.2.4. Detrended First-Order Conditions}

We will use small letters for growth-detrended variables. Specifically, let

$$
\begin{aligned}
c_{i t} & =\frac{C_{i t}}{N_{i t}\left(1+\gamma_{y}\right)^{t}}=\frac{C_{i t}}{n_{i t}\left(1+\gamma_{Y}\right)^{t}} \\
y_{i t}^{j} & =\frac{Y_{i t}^{j}}{N_{i t}\left(1+\gamma_{y}\right)^{t}}=\frac{Y_{i t}^{j}}{n_{i t}\left(1+\gamma_{Y}\right)^{t}} \\
l_{i t} & =\frac{L_{i t}}{N_{i t}}, l_{i t}^{j}=\frac{L_{i t}^{j}}{N_{i t}} \\
w_{i t} & =\frac{W_{i t}}{\left(1+\gamma_{y}\right)^{t}}
\end{aligned}
$$




$$
\begin{aligned}
k_{\cdot, i t}^{j} & =\frac{K_{,, i t}^{j}}{N_{i t}\left(1+\gamma_{y}\right)^{t}}=\frac{K_{\cdot, i t}^{j}}{n_{i t}\left(1+\gamma_{Y}\right)^{t}} \\
x_{,, i t}^{j} & =\frac{X_{\cdot, i t}^{j}}{N_{i t}\left(1+\gamma_{y}\right)^{t}}=\frac{X_{\cdot, i t}^{j}}{n_{i t}\left(1+\gamma_{Y}\right)^{t}} \\
x_{M, t}^{j} & =\frac{X_{M, t}^{j}}{\left(1+\gamma_{Y}\right)^{t}} \\
m_{t}^{j} & =\frac{M_{t}^{j}}{\left(1+\gamma_{Y}\right)^{t}} \\
d_{t}^{j} & =\frac{D_{t}^{j}}{\left(1+\gamma_{Y}\right)^{t}} \\
a_{i t}^{j} & =\frac{A_{i t}^{j}}{\left(1+\gamma_{A}\right)^{t}},
\end{aligned}
$$

where $\gamma_{Y}$ is the growth rate of output, $\gamma_{y}$ is the growth rate of per capita output, and $\gamma_{A}$ is the growth rate of TFP. Using the production technology, we can determine the growth rate of total output on the balanced growth trend:

$$
\begin{array}{r}
\left(1+\gamma_{Y}\right)=\left(1+\gamma_{A}\right)\left(1+\gamma_{N}\right)^{\phi}\left(1+\gamma_{Y}\right)^{\phi}\left(1+\gamma_{Y}\right)^{\alpha_{T}(1-\phi)} \\
\cdot\left(1+\gamma_{Y}\right)^{\alpha_{I}(1-\phi)}\left(1+\gamma_{N}\right)^{\left(1-\alpha_{T}-\alpha_{I}\right)(1-\phi)} \\
=\left(1+\gamma_{A}\right)^{\frac{1}{\left(1-\alpha_{T}-\alpha_{I}\right)(1-\phi)}}\left(1+\gamma_{N}\right)^{\frac{1-\left(\alpha_{T}+\alpha_{I}\right)(1-\phi)}{\left(1-\alpha_{T}-\alpha_{I}\right)(1-\phi)}}
\end{array}
$$

where recall that $\gamma_{N}$ is the growth rate of the population (and locations).

\section{B.2.5. Equilibrium Paths}

Substituting detrended variables into first-order conditions implies

$$
\begin{aligned}
\left(1+\gamma_{Y}\right) k_{T, i, t+1}^{j} & =\left[\left(1-\delta_{T}\right) k_{T, i t}^{j}+x_{T, i t}^{j}\right] n_{i t} / n_{i, t+1} \\
\left(1+\gamma_{Y}\right) k_{I, i, t+1}^{j} & =\left[\left(1-\delta_{I}\right) k_{I, i t}^{j}+x_{I, i t}^{j}\right] n_{i t} / n_{i, t+1} \\
\left(1+\gamma_{Y}\right) m_{t+1}^{j} & =\left[\left(1-\delta_{M}\right) m_{t}^{j}+x_{M, t}^{j}\right]
\end{aligned}
$$




$$
\begin{aligned}
d_{t}^{j}= & \sum_{i}\left\{\left(1-\tau_{p, i t}\right) n_{i t}\left(y_{i t}^{j}-w_{i t} l_{i t}^{j}-\delta_{T} k_{T, i t}^{j}-x_{I, i t}^{j}\right)\right\} \\
& -x_{M, t}^{j} \sum_{i}\left(1-\tau_{p, i t}\right) \chi_{i}^{j}-\sum_{i}\left\{n_{i, t+1}\left(1+\gamma_{Y}\right) k_{T, i, t+1}^{j}-n_{i t} k_{T, i t}^{j}\right\} \\
y_{i t}^{j}= & a_{i t}^{j}\left(m_{t}^{j}\right)^{\phi}\left(\left(k_{T, i t}^{j}\right)^{\alpha_{T}}\left(k_{I, i t}^{j}\right)^{\alpha_{I}}\left(l_{i t}^{j}\right)^{1-\alpha_{T}-\alpha_{I}}\right)^{1-\phi} \\
\sum_{i, j} n_{i t} y_{i t}^{j}= & \sum_{i} n_{i t}\left(c_{i t}+\bar{x}_{n b, i t}-\bar{y}_{n b, i t}+\sum_{j} x_{T, i t}^{j}+\sum_{j} x_{I, i t}^{j}\right)+\sum_{j} x_{M, t}^{j} \\
p_{t} / p_{t+1}= & \left(1+\gamma_{y}\right) c_{i, t+1} /\left(\beta c_{i t}\right) \\
p_{t} / p_{t+1}= & 1+r_{b, t+1} \\
\left(1-\tau_{l i}\right) w_{i t}= & \psi\left(1+\tau_{c i}\right) c_{i t} /\left(1-l_{i t}-l_{n b, i t}\right) \\
w_{i t}= & (1-\phi)\left(1-\alpha_{T}-\alpha_{I}\right) y_{i t}^{j} / l_{i t}^{j}, \quad \text { all } j \\
r_{T, i t}^{j}= & (1-\phi) \alpha_{T} y_{i t}^{j} / k_{T, i t}^{j} \\
r_{T, i t}^{j}= & (1-\phi) \alpha_{I} y_{i t}^{j} / k_{I, i t}^{j} \\
r_{M, i t}^{j}= & \phi n_{i t} y_{i t}^{j} / m_{t}^{j},
\end{aligned}
$$

where $\sum_{i} \chi_{i}^{j}=1$. In equilibrium, $\sum_{i} S_{i}^{j}=1$ and $\sum_{i} B_{i}=0$.

In the case of two countries, computing equilibrium paths involves solving a fixed point problem of size $T \times 11$, where $T$ is the length of the time series and 11 is the number of unknowns. The unknowns are as follows: $c_{i t}, l_{i t}, k_{T, i t}^{j}, m_{t}^{j}$, for all $i$ and $j$, and one asset holding. Because asset returns are equated deterministically, we preset $b_{i t}$ and $S_{i t}^{j}$ for one $j$ and $i$ and include $S_{-i t}^{-j}$ in the list of unknowns, where superscript $-j$ means "not $j$ " and subscript $-i$ means "not $i$." The fact that bond holdings sum to zero and share holdings sum to 1 implies all other asset holdings.

Given values for consumption, labor, tangible capital, technology capital, and asset holdings, we use a subset of first-order conditions to infer all remaining variables, and then we check that the remaining 11 first-order conditions hold-namely, the two budget 
constraints of the households, the two labor market clearing conditions, four Euler equations for tangible capital stocks, two Euler equations for technology capital stocks, and one Euler equation for foreign bonds. It turns out that the plant-specific intangible stocks are proportional to tangible stocks.

We choose initial capital stocks to ensure that investments do not jump at the start of our sample. Specifically, we add constraints that the growth in detrended investment between the first and second period is equal to the growth in detrended investment between the second and third period. We also set initial U.S. GDP to 1 and initial rest of world GDP to 2.2, which determines the scale for initial U.S. total factor productivity (TFP) and a scale for the ratio of intangible to tangible capital.

\section{B.2.6. Steady State}

We do not linearize around a steady state when computing equilibria, but the steady state is useful for gaining intuition about our solutions.

The steady state in this economy can be computed as follows. Given parameters, guess $c_{i}, l_{i}$, and $m^{j}$ and compute

$$
\begin{aligned}
& r_{b}=\left(1+\gamma_{y}\right) / \beta-1 \\
& w_{i}=\psi\left(1+\tau_{c i}\right) /\left[\left(1-\tau_{l i}\right)\left(1-l_{i}-\bar{l}_{n b, i}\right)\right] \text {, all } i \\
& y_{i}^{1} / l_{i}^{1}=w_{i} /\left((1-\phi)\left(1-\alpha_{T}-\alpha_{I}\right)\right), \text { all } i \\
& y_{i}^{j} / l_{i}^{j}=y_{i}^{1} / l_{i}^{1}, \text { all } i, j=2, \ldots, J \\
& k_{T, i}^{j} / y_{i}^{j}=\left((1-\phi) \alpha_{T}\right) /\left(r_{b} /\left(1-\tau_{p i}\right)+\delta_{T}\right) \text { all } i, j \\
& k_{I, i}^{j} / y_{i}^{j}=\left((1-\phi) \alpha_{I}\right) /\left(r_{b}+\delta_{I}\right), \quad \text { all }, i, j \\
& y_{i}^{j}=\left[a_{i}^{j}\left(k_{T, i}^{j} / y_{i}^{j}\right)^{(1-\phi) \alpha_{T}}\left(k_{I, i}^{j} / y_{i}^{j}\right)^{(1-\phi) \alpha_{I}}\left(l_{i}^{j} / y_{i}^{j}\right)^{(1-\phi)\left(1-\alpha_{T}-\alpha_{I}\right)}\right]^{1 / \phi} m^{j}, \text { all } i, j \\
& \Rightarrow \text { values for } k_{T, i}^{j}, k_{I, i}^{j}, l_{i}^{j} \text { given ratios above }
\end{aligned}
$$




$$
\begin{aligned}
& d^{j}=\sum_{i} n_{i}\left\{\left(1-\tau_{p i}\right)\left(y_{i}^{j}-w_{i} l_{i}^{j}-\delta_{T} k_{T, i}^{j}-\left(\gamma_{Y}+\delta_{I}\right) k_{I, i}^{j}\right)\right. \\
&\left.\quad-\gamma_{Y} k_{T, i}^{j}\right\}-\left(\gamma_{Y}+\delta_{M}\right) m^{j} \sum_{i}\left(1-\tau_{p i}\right) \chi_{i}^{j} \text { all } j \\
& \kappa_{i}=\tau_{c i} c_{i}+ \tau_{l i} w_{i} l_{i}+\tau_{d} \sum_{j} s_{i}^{j} d^{j} / n_{i} \\
&+\tau_{p i} \sum_{j}\left(y_{i}^{j}-w_{i} l_{i}^{j}-\delta_{T} k_{T, i}^{j}\right. \\
&\left.-\left(\gamma_{Y}+\delta_{I}\right) k_{I, i}^{j}-\left(\gamma_{Y}+\delta_{M}\right) \chi_{i}^{j} m^{j} / n_{i}\right)+\bar{y}_{n b, i}-\bar{x}_{n b, i} .
\end{aligned}
$$

With these intermediate results, we check that

$$
\begin{aligned}
l_{i} & =\sum_{j} l_{i}^{j}, \text { all } i \\
\left(r_{b}-\gamma_{Y}\right) b_{i} & =\left(1+\tau_{c i}\right) c_{i}-\left(1-\tau_{l i}\right) w_{i} l_{i}-\left(1-\tau_{d}\right) \sum_{j} s_{i}^{j} d^{j} / n_{i}-\kappa_{i}, \text { all } i \\
r_{b}-\delta_{M} & =\sum_{i}\left(1-\tau_{p i}\right)\left(\phi n_{i} y_{i}^{j} / m^{j}\right) / \sum_{i}\left(1-\tau_{p i}\right) \chi_{i}^{j}, \text { all } j .
\end{aligned}
$$

If it does not, we update the guess and continue.

To make sure all is adding up, we also double-check the global resource constraint:

$$
\sum_{i} n_{i} c_{i}+\sum_{i, j} n_{i} x_{T, i}^{j}+\sum_{i, j} n_{i} x_{I, i}^{j}+\sum_{j} x_{M}^{j}+\sum_{i} n_{i} \bar{x}_{n b, i}=\sum_{i, j} n_{i} y_{i}^{j}+\sum_{i} n_{i} \bar{y}_{n b, i} .
$$

\section{B.2.7. International Equity Values}

Assuming the total shares of multinational $j$ are normalized to 1 , the market value of $j$ is $V_{t}^{j}$. We next guess and verify that

$$
V_{t}^{j}=\left(1-\tau_{d t}\right)\left(\sum_{i} K_{T, i, t+1}^{j}+\sum_{i}\left(1-\tau_{p, i t}\right) K_{I, i, t+1}^{j}+\sum_{i}\left(1-\tau_{p, i t}\right) \chi_{i}^{j} M_{t+1}^{j}\right) .
$$

Using this guess, we have

$$
V_{t+1}^{j}+\left(1-\tau_{d, t+1}\right) D_{t+1}^{j}
$$




$$
\begin{aligned}
& =\left(1-\tau_{d, t+1}\right)\left(\sum_{i} K_{T, i, t+2}^{j}+\sum_{i}\left(1-\tau_{p, i, t+1}\right) K_{I, i, t+2}^{j}+\sum_{i}\left(1-\tau_{p, i, t+1}\right) \chi_{i}^{j} M_{t+2}^{j}\right) \\
& +\left(1-\tau_{d, t+1}\right) \sum_{i}\left\{( 1 - \tau _ { p , i , t + 1 } ) \left(Y_{i, t+1}^{j}-W_{i, t+1} L_{i, t+1}^{j}-\delta_{T} K_{T, i, t+1}^{j}\right.\right. \\
& -\left[K_{I, i, t+2}^{j}-\left(1-\delta_{I}\right) K_{I, i, t+1}^{j}\right] \\
& \left.\left.-\chi_{i}^{j}\left[M_{t+2}^{j}-\left(1-\delta_{M}\right) M_{t+1}^{j}\right]\right)\right\} \\
& -\left(1-\tau_{d, t+1}\right) \sum_{i}\left(K_{T, i, t+2}^{j}-K_{T, i, t+1}^{j}\right) \\
& =\left(1-\tau_{d, t+1}\right) \sum_{i}\left\{\left[\left(1-\tau_{p, i, t+1}\right)\left(r_{T, i, t+1}^{j}-\delta_{T}\right)+1\right] K_{T, i, t+1}^{j}\right. \\
& +\left[\left(1-\tau_{p, i, t+1}\right)\left(r_{T, i, t+1}^{j}+1-\delta_{I}\right)\right] K_{I, i, t+1}^{j} \\
& \left.+\left[\left(1-\tau_{p, i, t+1}\right)\left(r_{M, i, t+1}^{j}+\chi_{i}^{j}\left(1-\delta_{M}\right)\right)\right] M_{t+1}^{j}\right\} \\
& =\left(1-\tau_{d t}\right) \sum_{i}\left\{p_{t} / p_{t+1} K_{T, i, t+1}^{j}\right. \\
& +p_{t} / p_{t+1}\left(1-\tau_{p, i t}\right) K_{I, i, t+1}^{j} \\
& \left.+p_{t} / p_{t+1}\left(\sum_{i}\left(1-\tau_{p, i, t+1}\right) \chi_{i}^{j}\right) M_{t+1}^{j}\right\} \\
& =p_{t} / p_{t+1} V_{t}^{j},
\end{aligned}
$$

which verifies the guess because it is consistent with the household's first-order condition derived above.

\section{B.3. BEA Accounts}

Before comparing the model accounts to the BEA accounts for the United States, we make three adjustments to U.S. GNP and its components. First, we subtract consumption taxes from NIPA Table 3.5. Second, we subtract personal business expenses for handling life insurance and pension funds (found in NIPA Table 2.5.5) and treat them as intermediate financial services. Third, we add consumer durable depreciation (in Flow of Funds Table F10) and capital services for consumer durables and government capital services. The 
capital stocks for consumer durables and government capital are found in the BEA's Fixed Asset Table 1.1.10

We now apply the BEA's procedure to set up the national and international accounts for our economy. This implies the following for GDP and GNP and their components:

- $\mathrm{GDP}_{i t}=\sum_{j}\left(Y_{i t}^{j}-X_{I, i t}^{j}-\chi_{i}^{j} X_{M, t}^{j}\right)+\bar{Y}_{n b, i t}$

Income

Depreciation: $\delta_{T} \sum_{j} K_{T, i t}^{j}$

Compensation: $W_{i t} \sum_{j} L_{i t}^{j}=W_{i t} L_{i t}$

Profits:

Tax liability: $\tau_{p, i t} \sum_{j}\left(Y_{i t}^{j}-W_{i t} L_{i t}^{j}-\delta_{T} K_{T, i t}^{j}-X_{I, i t}^{j}-\chi_{i}^{j} X_{M, t}^{j}\right)$

Dividends: $\sum_{j}\left\{\left(1-\tau_{p, i t}\right)\left(Y_{i t}^{j}-W_{i t} L_{i t}^{j}-\delta_{T} K_{T, i t}^{j}-X_{I, i t}^{j}-\chi_{i}^{j} X_{M, t}^{j}\right)\right.$

$$
\left.-\left(K_{T, i, t+1}^{j}-K_{T, i t}^{j}\right)\right\}
$$

Retained earnings: $\sum_{j}\left(K_{T, i, t+1}^{j}-K_{T, i t}^{j}\right)$

Nonbusiness income: $\bar{Y}_{n b, i t}$

Product

Consumption: $C_{i t}$

Measured investment: $\sum_{j} X_{T, i t}^{j}+\bar{X}_{n b, i t}$

Net exports: $\sum_{j}\left(Y_{i t}^{j}-X_{I, i t}^{j}-\chi_{i}^{j} X_{M, t}^{j}-X_{T, i t}^{j}\right)-C_{i t}+\bar{Y}_{n b, i t}-\bar{X}_{n b, i t}$

- $\mathrm{GNP}_{i t}=\mathrm{GDP}_{i t}+$ Net factor receipts less payments

Net factor receipts (from $l \neq i$ )

Direct investment: $\sum_{l \neq i}\left(1-\tau_{p, l t}\right) \sum_{j \in J^{i}}\left(Y_{l t}^{j}-W_{l t} L_{l t}^{j}-\delta_{T} K_{T, l t}^{j}-X_{I, l t}^{j}-\chi_{l}^{j} X_{M, t}^{j}\right)$

Portfolio equity: $\sum_{j \in J^{l}} S_{i t}^{j} D_{t}^{j}$

Portfolio interest: $r_{b t} B_{i t}$ if $B_{i t} \geq 0$

Net factor payments $($ to $l \neq i$ )

Direct investment: $\left(1-\tau_{p, i t}\right) \sum_{j \in J^{l}}\left(Y_{i t}^{j}-W_{i t} L_{i t}^{j}-\delta_{T} K_{T, i t}^{j}-X_{I, i t}^{j}-\chi_{i}^{j} X_{M, t}^{j}\right)$

Portfolio equity: $\sum_{l \neq i} \sum_{j \in J^{i}} S_{l t}^{j} D_{t}^{j}$

10 See more details in the Matlab code accounts.m. This program loads in BEA and Flow of Funds original data files and writes out Table 4 of the main paper. 
Portfolio interest: $r_{b t} B_{i t}$ if $B_{i t} \leq 0$

- Balance of Payments: Current account = Financial account

Current account

Net exports

Net factor receipts less payments

Financial account

Direct investment: $\sum_{l \neq i} \sum_{j \in J^{i}}\left(K_{T, l, t+1}^{j}-K_{T, l t}^{j}\right)-\sum_{j \in J^{l}}\left(K_{T, i, t+1}^{j}-K_{T, i t}^{j}\right)$

Portfolio equity: $\sum_{j \in J^{l}} V_{t}^{j}\left(S_{i, t+1}^{j}-S_{i t}^{j}\right)-\sum_{l \neq i} \sum_{j \in J^{i}} V_{t}^{j}\left(S_{l, t+1}^{j}-S_{l t}^{j}\right)$

Portfolio debt: $B_{i, t+1}-B_{i t}$

It is useful to examine the current account and financial account for a two-country case, since we can relate it to the household budget constraints. Let $u$ be the United States and $r$ be the rest of world. We will index companies in the United States by $d$, which we will refer to as "Dell" (or alternatively "Domestic"). We will index rest-of-world companies by $f$, which we will refer to as "Fujitsu" (or alternatively "Foreign"). We will assume full expensing at home.

In this case, the current account can be written as net exports $(N X)$ plus net factor receipts (NFR) less net factor payments (NFP):

$$
\begin{aligned}
\mathrm{CA}_{u t}= & N X_{u t}+\mathrm{NFR}_{u t}-\mathrm{NFP}_{u t} \\
= & {\left[Y_{u t}^{d}+Y_{u t}^{f}-X_{I, u t}^{d}-X_{I, u t}^{f}-X_{T, u t}^{d}-X_{T, u t}^{f}-X_{M, t}^{d}+\bar{Y}_{n b, u t}-\bar{X}_{n b, u t}-C_{u t}\right] } \\
+ & {\left[\left(1-\tau_{p, r t}\right)\left(Y_{r t}^{d}-W_{r t} L_{r t}^{d}-\delta_{T} K_{T, r t}^{d}-X_{I, r t}^{d}\right)+S_{u t}^{f} D_{t}^{f}\right] } \\
- & {\left[\left(1-\tau_{p, u t}\right)\left(Y_{u t}^{f}-W_{u t} L_{u t}^{f}-\delta_{T} K_{T, u t}^{f}-X_{I, u t}^{f}\right)+S_{r t}^{d} D_{t}^{d}-r_{b} B_{u t}\right] } \\
= & \left(1-\tau_{l u}\right) W_{u t} L_{u t}+\left(1-\tau_{d t}\right) \sum_{j} S_{u t}^{j} D_{t}^{j}+r_{b t} B_{u t}+\kappa_{u t}-\left(1-\tau_{c u}\right) C_{u t} \\
& \quad+K_{T, r, t+1}^{d}-K_{T, r t}^{d}-K_{T, u, t+1}^{f}+K_{T, u t}^{f},
\end{aligned}
$$


where

$$
\begin{aligned}
\kappa_{u t} & =\tau_{c u} C_{u t}+\tau_{l u} W_{u t} L_{u t}+\tau_{d t}\left(S_{u t}^{d} D_{t}^{d}+S_{u t}^{f} D_{t}^{f}\right) \\
& +\tau_{p, u t}\left(Y_{u t}-W_{u t} L_{u t}-\delta_{T} K_{T, u t}-X_{I, u t}\right)+\bar{Y}_{n b, u t}-\bar{X}_{n b, u t},
\end{aligned}
$$

$Y_{i t}$ is total production in country $i, K_{T, i t}=\sum_{j} K_{T, i t}^{j}$ the total tangible capital stock in country $i$, and $X_{I, i t}=\sum_{j} X_{I, i t}^{j}$ is total plant-specific investment in country $i$. In writing net factor payments, we assume that $B_{u t}<0$ and therefore net factor interest is paid by the United States to rest of world.

Next, consider the financial account (FA), which is the change in assets and given by

$$
\begin{aligned}
\mathrm{FA}_{u t} & =\left[K_{T, r, t+1}^{d}-K_{T, r t}^{d}-V_{t}^{d}\left(S_{r, t+1}^{d}-S_{r t}^{d}\right)\right] \\
& -\left[K_{T, u, t+1}^{f}-K_{T, u t}^{f}-V_{t}^{f}\left(S_{u, t+1}^{f}-S_{u t}^{f}\right)\right]+B_{u, t+1}-B_{u t} \\
& =\sum_{j} V_{t}^{j}\left(S_{u, t+1}^{j}-S_{u t}^{j}\right)+B_{u, t+1}-B_{u t} \\
& +K_{T, r, t+1}^{d}-K_{T, r t}^{d}-K_{T, u, t+1}^{f}+K_{T, u t}^{f},
\end{aligned}
$$

where we use the fact that $\sum_{i} S_{i t}^{j}=1$ for all $t$. By the balance of payments, FA less CA is equal to zero and therefore

$$
\begin{aligned}
\left(1-\tau_{c u}\right) C_{u t} & +\sum_{j} V_{t}^{j}\left(S_{u, t+1}^{j}-S_{u t}^{j}\right)+B_{u, t+1}-B_{u t} \\
& =\left(1-\tau_{l u}\right) W_{u t} L_{u t}+\left(1-\tau_{d t}\right) \sum_{j} S_{u t}^{j} D_{t}^{j}+r_{b t} B_{u t}+\kappa_{u t},
\end{aligned}
$$

which in turn implies that the household period $t$ budget holds each period.

Net foreign asset positions in the BEA's international accounts are based on the flows from the financial account, with adjustments made for capital gains. Unfortunately, because of several unavoidable measurement problems, the foreign net asset position concept is flawed. First, in a world with intangible capital that is expensed, part of the FA earnings 
are not counted. Even if they could be estimated, the part of intangible capital that is technology capital is neither domestic nor foreign. Finally, without decent transaction prices for capital stock abroad, an inevitable mismatch occurs when we add portfolio incomes and direct investment retained earnings.

We asked ourselves, is there a natural alternative to the BEA's net foreign asset position measure? Unfortunately, the answer is no for our economy.

\section{B.4. Sensitivity of Main Results}

In this section we perform sensitivity analyses. Specifically, we rerun the exercise described in the main paper for alternative parameterizations of the model economy, varying parameters for which we have little independent information. For convenience, we report the benchmark constants in Table B.1 of this appendix. In Table B.2 we report the benchmark time-varying inputs.

The experiments are conducted as follows. For each alternative set of model constants, we choose the path for the openness parameters and the relative size so as to mimic trends in the U.S. current account. ${ }^{11}$ We set the initial capital stocks so that initial U.S. GDP is 31 percent of initial world GDP and so that there are no jumps in initial investments. The initial U.S. TFP is set so that initial U.S. GDP is normalized to 1.

We also investigate the impact of the openness parameters and the (residual) choice of the weight on foreign stocks in U.S. portfolios. The benchmark inputs are shown in Table B.2. In the first experiment, we fix the openness parameters at the benchmark 1960 level throughout the sample. In the second experiment, we fix the U.S. share of foreign equities. In both experiments, we adjust the relative size of the rest of world to the United

11 We also set portfolio weights so that the model generates the right split of debt and equity net factor incomes. Later, we show that the impact of this choice is negligible for our main findings. 
States to fit the trend in U.S. net exports relative to GNP. As in the benchmark economy, this is done by adjusting the relative TFPs.

Our results are reported in Tables B.3 and B.4. Table B.3 reports the model's predictions for average investment shares and capital to output ratios for the period 1960-2006 and business valuations for U.S. companies relative to GNP in the 1960s. These estimates were used when choosing the benchmark parameters. In Table B.4 we report the predicted returns on foreign direct investment for U.S. companies and rest of world companies. The prediction for these returns is the central finding of the paper. For comparison, we include predictions of the benchmark model in both tables and returns based on BEA data in Table B.4. All returns are constructed using the same procedure as the BEA for their current-cost measures.

The sensitivity analysis summarized in Tables B.3 and B.4 highlights the role that rents from technology capital and plant-specific intangible capital play in raising measured FDI returns and the role that investment in plant-specific capital plays in lowering measured foreign returns. As we discussed in the main text, the return on foreign direct investment in country $i$ made by companies from $j, r_{F D I, i t}^{j}$ relative to the true return $r_{t}$ to capital (of all types) is given by

$$
r_{F D I, i t}^{j}-r_{t}=\left(1-\tau_{p, i t}\right)\left[\phi+(1-\phi) \alpha_{I}\right] \frac{Y_{i t}^{j}}{K_{T, i t}^{j}}-\left(1-\tau_{p, i t}\right) \frac{X_{I, i t}^{j}}{K_{T, i t}^{j}} .
$$

The first term is the excess return due to profits on technology capital and plant-specific capital. The second term is the discount in return due to expensed investment in plantspecific intangible capital.

In our sensitivity analysis, as we vary the depreciation rate of technology capital $\delta_{M}$ we find significant changes in predicted investments, stocks, and valuations, but negligible changes in the returns to FDI. The results of these experiments are shown in rows 1 and 2 of Tables B.3 and B.4. Returns are little changed because the technology capital 
depreciation rate has a negligible impact on the tangible capital to output ratio and a negligible impact on the share of plant-specific investment. The choice of $\delta_{M}$ equal to 8 percent implies a technology capital to GNP ratio in the range of 5 to 6 percent and a U.S. business value to GNP ratio between 1.5 and 1.6 in the 1960s. These were the targets used when parameterizing the benchmark model.

When we vary intangible income shares and the depreciation rate of plant-specific intangible capital, we find a nonnegligible effect on FDI returns. Consider first the income share on technology capital $\phi$. The benchmark value is 7 percent. We experimented with $\phi=8$ percent and $\phi=6$ percent and, as before, changed the exogenous inputs to ensure that the model generates the same trends in current account flows. The results show that these alternate specifications have a nonnegligible effect on both the macro quantities in Table B.3 and on FDI returns in Table B.4.

Interestingly, in Table B.3, we see that the investment share for plant-specific capital rises with $\phi$ while the ratio of plant-specific capital to output falls. This finding is due to the fact that the initial capital stocks are also changed in each experiment to ensure that the auxiliary constraints on initial investments and initial GDPs hold for each experiment. The magnitude of the capital stocks in turn affects the business valuations. A value of $\phi=7$ percent implies that the model's prediction for the 1960s U.S. business value to GNP is in the range of 1.5 to 1.6 .

In rows 3 and 4 of Table B.4, we report the predicted returns on FDI. As is evident from (B.4.1), there is a direct effect of changing $\phi$ through the first term and indirect effects through changes in investment shares and capital to output ratios. With $\phi=8$ percent, we find an increase in both the return on U.S. direct investment abroad and the return on FDI in the United States. The former increases by 60 basis points and the latter by 66 basis points. Thus, there is a slight narrowing of the return gap. With $\phi=6$ percent, the opposite occurs: both the return on U.S. direct investment abroad and the return on 
direct investment in the United States are lower. The impact is nonlinear, however, since the gap widens by more than 6 basis points. In fact, with $\phi=6$ percent, the return gap is 426 basis points, which is close to 70 percent of the actual gap.

Like $\phi$, the income share $\alpha_{I}$ has a direct effect on the excess return in (B.4.1). However, technology capital and plant-specific intangible capital affect the FDI return differently because one is expensed at home and the other abroad. In the case of foreign plantspecific intangible capital, what matters is the timing of expensing, since it directly lowers the return in (B.4.1). Therefore, what matters is not the choice of the income share $\alpha_{I}$ alone or the the choice of the depreciation rate $\delta_{I}$ alone, but rather the pair.

In rows 5 and 6 of Tables B.3 and B.4, we show the results as we vary $\delta_{I}$ and $\alpha_{I}$. We first increased $\delta_{I}$ from 0 in the benchmark to 6 percent, which is equal to the rate used for tangible capital. This change has the effect of cutting the average plant-specific intangible capital to output ratio in half, from 1.2 times GNP to 0.6 times GNP, and the average ratio of plant-specific intangible capital to tangible capital by even more, from 0.91 to 0.39 . The lower intangible capital stock implies a lower 1960s business value to GNP ratio, although the impact is partially offset by the fact that companies substitute across types of capital. The effect on FDI returns shows up in a higher predicted return on FDI in the United States. Less expensed investment implies a smaller negative term in (B.4.1). The predicted return for FDI in the United States, then, is 4.3 percent, which is higher than the roughly 3.1 percent return in the benchmark economy and the U.S. data. Interestingly, even with a ratio of plant-specific intangible capital to tangible capital of less than 40 percent, the return gap is still 270 basis points.

We find a much wider FDI return gap when we increase $\alpha_{I}$ from 7 percent in the benchmark economy to 10 percent. In this case, expensing of plant-specific intangible capital plays a much bigger role and the predicted return on FDI in the United States is 
only 2.54 percent, which is lower than the roughly 3.1 percent return in the benchmark economy and the U.S. data.

In rows 7 and 8 of Tables B.3 and B.4, we show that varying tax rates on consumption and labor have almost no effect on investments and returns.

In the last three rows of Tables B.3 and B.4, we report results for alternative specifications of time-varying inputs. Row 9 has results for an alternative projection of rest of world population. The benchmark economy (in Table B.2) has the ratio of relative populations falling after 2010 at the same rate as the most recent decade. In the alternative specification, we assume the ratio of populations does not fall further after 2010. The results show that the predictions in this case are very close to the benchmark. The FDI return gap increases, but only slightly.

In row 10 are results for a constant U.S. share of foreign equity, $S_{u t}^{f}$, equal to the initial level of 1 percent. Recall that in the benchmark economy, we needed to assume a large shift in shares in 2000 to get the timing in the difference between receipts and payments of equity portfolio income to match the U.S. time series. This seems implausible and is likely due to our strong assumption that there are no differences in returns due to risk. In Tables B.3 and B.4, we show that the choice of path for $S_{u t}^{f}$ does not affect our main findings. For the case of a constant share, the average return gap is different from the benchmark economy by only 4 basis points.

In the final experiment, we investigate the model's predictions if the U.S. and rest of world economies had not opened up further relative to where they were in 1960. This is clearly counterfactual given the large rise in FDI incomes, but we are interested in investigating the impact of our choice of openness parameters. In this experiment, we only adjust the relative TFPs to ensure that the trend in net exports to GNP is the same in this case as in the benchmark. 
With no change in openness, both measured returns on FDI are high-roughly 7.9 percent per year-relative to the actual annual return, which is roughly 4.6 percent per year on all types of capital. ${ }^{12}$ The gap is approximately zero because foreign companies do not significantly increase their investments in their U.S. subsidiaries with openness parameters expected to be constant.

12 Since we model trends, we set the period equal to five years when computing equilibria. In our experiments, the actual arithmetic return is 4.6 percent per year and the actual geometric return is 4.2 percent per year. 
TaBle B.1. Model Constants at Annual Rates

\begin{tabular}{|c|c|c|}
\hline Parameter & EXPRESSION & VALUE \\
\hline \multicolumn{3}{|l|}{ Growth Rates (\%) } \\
\hline Population & $\gamma_{N}$ & 1.0 \\
\hline Technology & $\gamma_{A}$ & 1.2 \\
\hline \multicolumn{3}{|l|}{ Preferences } \\
\hline Discount factor & $\beta$ & .98 \\
\hline Leisure weight & $\psi$ & 1.32 \\
\hline \multicolumn{3}{|l|}{ Nonbusiness Sector (\%) } \\
\hline Fraction of time at work, $i=u, r$ & $\bar{L}_{n b, i} / N_{i}$ & 6.0 \\
\hline Nonbusiness investment, $i=u, r$ & $\bar{X}_{n b, i} / \mathrm{GDP}_{i}$ & 15.4 \\
\hline Nonbusiness value added, $i=u, r$ & $\bar{Y}_{n b, i} / \mathrm{GDP}_{i}$ & 31.2 \\
\hline \multicolumn{3}{|l|}{ Fixed Tax Rates (\%) } \\
\hline Tax rates on labor $i=u, r$ & $\tau_{l, i}$ & 29.0 \\
\hline Tax rate on consumptions, $i=u, r$ & $\tau_{c, i}$ & 7.3 \\
\hline \multicolumn{3}{|l|}{ Income Shares (\%) } \\
\hline Technology capital & $\phi$ & 7.0 \\
\hline Tangible capital & $(1-\phi) \alpha_{T}$ & 21.4 \\
\hline Plant-specific intangible capital & $(1-\phi) \alpha_{I}$ & 6.5 \\
\hline Labor & $(1-\phi)\left(1-\alpha_{T}-\alpha_{I}\right)$ & 65.1 \\
\hline \multicolumn{3}{|l|}{ Depreciation Rates (\%) } \\
\hline Technology capital & $\delta_{M}$ & 8.0 \\
\hline Tangible capital & $\delta_{T}$ & 6.0 \\
\hline Plant-specific intangible capital & $\delta_{I}$ & 0 \\
\hline
\end{tabular}


TABle B.2. Model Time-Varying Inputs

\begin{tabular}{|c|c|c|c|c|c|c|c|c|}
\hline \multirow[b]{2}{*}{ Year } & \multirow{2}{*}{$\begin{array}{c}\text { Relative }^{a} \\
\text { Populations }\end{array}$} & \multicolumn{2}{|c|}{ Tax Rates } & \multicolumn{2}{|c|}{ Openness } & \multirow{2}{*}{$\begin{array}{c}\text { Relative }^{a} \\
\text { TFPs } \\
\end{array}$} & \multirow{2}{*}{$\begin{array}{c}\text { Per } \\
\text { Capita } \\
\text { U.S. Debt }\end{array}$} & \multirow{2}{*}{$\begin{array}{c}\text { U.S. } \\
\text { Foreign } \\
\text { Shares } \\
\end{array}$} \\
\hline & & Dividends & Profits & ROW & U.S. & & & \\
\hline 1960 & 8.20 & .400 & 408 & 8350 & .6900 & .3730 & 0 & .010 \\
\hline 1965 & 8.42 & .400 & .403 & .8397 & .6942 & .3727 & 0 & .032 \\
\hline 1970 & 8.64 & .400 & .396 & .8443 & .7003 & .3725 & 0 & .050 \\
\hline 1975 & 8.86 & .397 & .386 & .8490 & .7090 & .3722 & 0 & .070 \\
\hline 1980 & 9.08 & .370 & .375 & .8537 & .7207 & .3719 & 0 & .113 \\
\hline 1985 & 9.30 & .246 & .361 & .8583 & .7357 & .3714 & -.049 & .178 \\
\hline 1990 & 9.37 & .164 & .348 & .8630 & .7531 & .3717 & -.098 & .220 \\
\hline 1995 & 9.28 & .153 & .336 & .8677 & .7718 & .3731 & -.146 & .260 \\
\hline 2000 & 9.16 & .152 & .327 & .8723 & .7899 & .3743 & -.195 & .300 \\
\hline 2005 & 9.04 & .152 & .320 & .8770 & .8058 & .3751 & -.244 & -.050 \\
\hline 2010 & 8.91 & .152 & .315 & .8817 & .8186 & .3743 & -.270 & .000 \\
\hline 2015 & 8.79 & .152 & .312 & .8863 & .8283 & .3732 & -.293 & .000 \\
\hline 2020 & 8.67 & .152 & .310 & .8910 & .8352 & .3723 & -.293 & .000 \\
\hline 2025 & 8.55 & .152 & .309 & .8957 & .8399 & .3721 & -.293 & .000 \\
\hline 2030 & 8.42 & 152 & .308 & .9003 & .8431 & .3731 & -.293 & .000 \\
\hline 2035 & 8.30 & .152 & .307 & .9050 & .8452 & .3745 & -.293 & .000 \\
\hline
\end{tabular}

$a$ "Relative" implies rest of world relative to the United States. 
TABle B.3. Alternative Model Predictions for Investments and Stocks ${ }^{a}$

\begin{tabular}{|c|c|c|c|c|c|c|}
\hline \multirow[b]{3}{*}{ Model } & \multicolumn{5}{|c|}{ Averages, 1960-2006 } & \multirow{3}{*}{$\begin{array}{c}1960 \mathrm{~s} \\
\text { Business } \\
\text { Value to } \\
\text { GNP } \\
\frac{V_{t}^{d}}{G N P_{u t}}\end{array}$} \\
\hline & \multirow{2}{*}{\multicolumn{2}{|c|}{$\begin{array}{l}\text { Intangible Investment } \\
\text { Divided by } \operatorname{GNP}(\%) \\
\frac{X_{M, t}^{d}}{G N P_{u t}} \quad \frac{\sum_{j} X_{I, u t}^{j}}{G N P_{u t}}\end{array}$}} & \multicolumn{2}{|c|}{$\begin{array}{l}\text { Intangible Stocks } \\
\text { Divided by GNP }\end{array}$} & \multirow{2}{*}{$\begin{array}{c}\text { Ratio of } \\
\text { Intangible } \\
\text { to Tangible } \\
\frac{K_{I, i t}^{j}}{K_{T, i t}^{j}}\end{array}$} & \\
\hline & & & $\frac{M_{t}^{d}}{G N P_{u t}}$ & $\frac{\sum_{j} K_{I, u t}^{j}}{G N P_{u t}}$ & & \\
\hline \multicolumn{7}{|l|}{ Alternatives: } \\
\hline$\delta_{M}=0 \%$ & 4.3 & 3.7 & 1.39 & 1.20 & 0.91 & 1.82 \\
\hline$\delta_{M}=16 \%$ & 5.5 & 3.9 & 0.37 & 1.20 & 0.91 & 1.45 \\
\hline$\phi=8 \%$ & 6.1 & 4.1 & 0.61 & 1.17 & 0.90 & 1.49 \\
\hline$\phi=6 \%$ & 4.4 & 2.9 & 0.47 & 1.34 & 0.96 & 1.61 \\
\hline$\delta_{I}=6 \%$ & 5.2 & 4.2 & 0.59 & 0.60 & 0.39 & 1.47 \\
\hline$\alpha_{I}=10 \%$ & 5.6 & 7.0 & 0.52 & 1.54 & 1.22 & 1.56 \\
\hline$\tau_{c}=40 \%$ & 5.3 & 3.9 & 0.53 & 1.21 & 0.91 & 1.51 \\
\hline$\tau_{l}=40 \%$ & 5.3 & 3.9 & 0.53 & 1.21 & 0.91 & 1.51 \\
\hline$\frac{n_{r t}}{n_{u t}}=8.8, t>2010$ & 5.3 & 3.6 & 0.54 & 1.24 & 0.92 & 1.54 \\
\hline$S_{u t}^{f}$ constant $^{b}$ & 5.3 & 4.1 & 0.53 & 1.16 & 0.89 & 1.47 \\
\hline$\sigma_{i t}$ constant $^{b}$ & 5.3 & 4.0 & 0.52 & 1.19 & 0.90 & 1.47 \\
\hline Benchmark & 5.3 & 3.9 & 0.53 & 1.20 & 0.91 & 1.51 \\
\hline
\end{tabular}

a Parameters and results are in annual units.

${ }^{b}$ Model FDI incomes are not matched to U.S. FDI incomes. 
TABle B.4. Alternative Model Predictions for FDi Returns, 1982-2006 ${ }^{a}$

\begin{tabular}{lccc}
\hline Model & $\begin{array}{c}\text { \% Return on U.S. } \\
\text { DI Abroad }\end{array}$ & $\begin{array}{c}\text { \% Return on FDI } \\
\text { in U.S. }\end{array}$ & Difference \\
\hline Alternatives: & & & \\
$\delta_{M}=0 \%$ & 7.03 & 3.12 & 3.91 \\
$\delta_{M}=16 \%$ & 7.09 & 3.12 & 3.97 \\
$\phi=8 \%$ & 7.63 & 3.78 & 3.85 \\
$\phi=6 \%$ & 6.59 & 2.33 & 4.26 \\
$\delta_{I}=6 \%$ & 7.00 & 4.30 & 2.70 \\
$\alpha_{I}=10 \%$ & 7.05 & 2.54 & 4.51 \\
$\tau_{c}=40 \%$ & 7.07 & 3.11 & 3.96 \\
$\tau_{l}=40 \%$ & 7.07 & 3.11 & 3.96 \\
$\frac{n_{r t}}{n_{u t}}=8.8, t>2010$ & 7.06 & 3.07 & 3.99 \\
$S_{u t}^{f}$ constant $^{b}$ & 7.10 & 3.15 & 3.95 \\
$\sigma_{i t}$ constant $^{b}$ & 7.90 & 7.93 & -.03 \\
\hline Benchmark & 7.08 & 3.12 & 3.96 \\
U.S. Data & 9.40 & 3.15 & 6.25 \\
\hline
\end{tabular}

${ }^{a}$ Parameters and results are in annual units.

${ }^{b}$ Model FDI incomes are not matched to U.S. FDI incomes. 


\section{Appendix C.}

\section{The Impact of Technology Capital on Productivity and Net Exports}

\section{C.1. Introduction}

In this appendix, we work with a simple version of the model presented in the main paper to gain intuition for some of the results. We refer to this simple model as the strippeddown model because we "strip out" taxation, plant-specific intangible capital, nonbusiness activities, and equities from our general model to make our analysis tractable. In the stripped-down version of the model, the only recorded transactions in the current account are net shipments of goods and net borrowing or lending. ${ }^{13}$

We use the stripped-down model to analytically characterize and contrast equilibria in economies with and without technology capital. We demonstrate that including technology capital in our stripped-down model - which is an otherwise standard two-country growth model - has an important impact on its predictions for relative labor productivities and net exports. In a standard model without technology capital, relative productivities and the level of borrowing and lending across countries depend only on countries' relative TFPs. When we include technology capital, we find that relative populations and the degree of countries' openness also matter. We demonstrate this in several propositions and then show equilibrium paths for several empirically motivated numerical examples.

The main lesson that we draw from the results is that the change in the relative

13 There are two Matlab codes that generate equilibrium paths shown in the figures of this appendix. The code nx_tcap.m generates results for the model with technology capital included, and nx_std.m generates results for the standard model without technology capital. 
populations was an important factor in the recent decline of the trade balance, and this fact is not captured by standard international models that abstract from technology capital.

\section{C.2. Stripped-Down Model}

We start with a stripped-down model. In order to make it easier to follow, we adopt the following notation: $u$ stands for United States, $r$ stands for rest of world, $d$ stands for Dell (a U.S. company), and $f$ stands for Fujitsu (a non-U.S. company).

We will consider both a planning problem (with utility weights $\lambda$ and $1-\lambda$ ) and a decentralized economy with borrowing and lending and some initial outstanding debt. The

allocations for the planner's problem and the decentralized economy are the same for a particular $\lambda$ in the planner's problem and initial debt in the decentralized problem.

The planner solves the following problem:

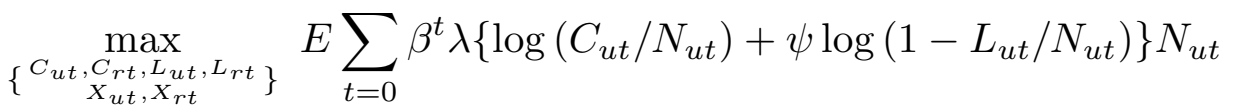

$$
\begin{aligned}
& +(1-\lambda)\left\{\log \left(C_{r t} / N_{r t}\right)+\psi \log \left(1-L_{r t} / N_{r t}\right)\right\} N_{r t},
\end{aligned}
$$

subject to the global resource constraint and the capital accumulation equations

$$
\begin{aligned}
& C_{u t}+C_{r t}+X_{K, u t}+X_{K, r t}+X_{M, t}^{d}+X_{M, t}^{f}=Y_{u t}+Y_{r t} \\
& K_{u, t+1}=(1-\delta) K_{u t}+X_{K, u t} \\
& K_{r, t+1}=(1-\delta) K_{r t}+X_{K, r t} \\
& M_{t+1}^{d}=(1-\delta) M_{t}^{d}+X_{M, t}^{d} \\
& M_{t+1}^{f}=(1-\delta) M_{t}^{f}+X_{M, t}^{f},
\end{aligned}
$$

with initial stocks $K_{i 0}, i=u, r$, and $M_{0}^{j}, j=d, f$ given.

The technologies available to the planner are given by

$$
Y_{u t}^{d}=A_{u t}\left(N_{u t} M_{t}^{d}\right)^{\phi}\left(\left(K_{u t}^{d}\right)^{\alpha}\left(L_{u t}^{d}\right)^{1-\alpha}\right)^{1-\phi}
$$




$$
\begin{aligned}
& Y_{u t}^{f}=\sigma_{u t} A_{u t}\left(N_{u t} M_{t}^{f}\right)^{\phi}\left(\left(K_{u t}^{f}\right)^{\alpha}\left(L_{u t}^{f}\right)^{1-\alpha}\right)^{1-\phi} \\
& Y_{r t}^{d}=\sigma_{r t} A_{r t}\left(N_{r t} M_{t}^{d}\right)^{\phi}\left(\left(K_{r t}^{d}\right)^{\alpha}\left(L_{r t}^{d}\right)^{1-\alpha}\right)^{1-\phi} \\
& Y_{r t}^{f}=A_{r t}\left(N_{r t} M_{t}^{f}\right)^{\phi}\left(\left(K_{r t}^{f}\right)^{\alpha}\left(L_{r t}^{f}\right)^{1-\alpha}\right)^{1-\phi}
\end{aligned}
$$

and aggregate output in country $i$ is $Y_{i t}=Y_{i t}^{d}+Y_{i t}^{f}, i=u, r$. In the standard model, $\phi=0$ and $\sigma_{i t}=0, i=u, r$. Note that the aggregate capital stocks and labor inputs in country $i$ are given by

$$
\begin{gathered}
K_{i t}=K_{i t}^{d}+K_{i t}^{f} \\
L_{i t}=L_{i t}^{d}+L_{i t}^{f},
\end{gathered}
$$

where $i=u$ or $r$.

The allocations for the planner's problem are equivalent to those of the following decentralized economy with borrowing and lending conditional on a particular value for initial debt. Here, households in country $u$ solve

$$
\max _{\left\{C_{u t}, L_{u t}\right\}} E \sum_{t=0}^{\infty} \beta^{t}\left\{\log \left(C_{u t} / N_{u t}\right)+\psi \log \left(1-L_{u t} / N_{u t}\right)\right\} N_{u t}
$$

subject to the period budget constraints and the capital accumulation equations,

$$
\begin{aligned}
& C_{u t}+X_{K, u t}+X_{M, t}^{d}+B_{t+1} \leq W_{u t} L_{u t}+r_{u t}^{k} K_{u t}+r_{d t}^{m} M_{t}^{d}+\left(1+r_{t}^{b}\right) B_{t} \\
& K_{u, t+1}=(1-\delta) K_{u t}+X_{u t} \\
& M_{t+1}^{d}=(1-\delta) M_{t}^{d}+X_{M, t}^{d}
\end{aligned}
$$

and initial conditions $K_{u 0}, M_{0}^{d}, B_{0}$. The household takes as given TFP, population and all prices, $\left\{A_{u t}, N_{u t}, W_{u t}, r_{u t}^{k}, r_{d t}^{m}, r_{t}^{b}\right\}$ given. The rest-of-world households solve a similar problem, specified by replacing $u$ with $r$ and $d$ with $f$. 
If we solve the planner's problem for a particular value of $\lambda$, we can construct the associated initial debt level for the decentralized economy as follows:

$$
B_{0}=\phi \sum_{t=0}^{\infty} \frac{\left(Y_{r t}^{d *}-Y_{u t}^{f *}\right)}{\Pi_{s=0}^{t}\left(1+r_{s}^{b}\right)}
$$

where $r_{s}^{b}=c_{u s}^{*} /\left(\beta c_{u, s-1}^{*}\right)-1, c_{u}^{*}$ is per capita U.S. consumption, and the asterisk denotes allocations of the planner's problem. Alternatively, if we solve the decentralized problem for a particular initial debt level, then the associated utility weight is

$$
\lambda=\frac{c_{u t}}{c_{u t}+c_{r t}}
$$

for any period $t$ allocation from the decentralized economy, where $c_{r}$ is per capita rest of world (ROW) consumption.

\section{C.3. Relative Labor Productivities}

In this section, we derive an expression for the relative labor productivities when there is no uncertainty and countries are not yet fully open. ${ }^{14}$ Of particular interest is a comparison of results for cases without technology capital $(\phi=0)$ and cases with technology capital $(\phi>0)$. The main results are summarized in Proposition 1.

Proposition 1. Assume $\sigma_{i t} \in[0,1), i=u, r$ and parameters are chosen so that companies in both countries have positive technology capital stocks. ${ }^{15}$ If $\phi=0$, then there is no foreign production, $Y_{u t}^{f}=Y_{r t}^{d}=0$ for all $t$, as long as the openness parameters are strictly less than 1. In this case, the relative labor productivities depend only on the relative TFPs:

$$
\frac{Y_{u t} / L_{u t}}{Y_{r t} / L_{r t}}=\left(\frac{A_{u t}}{A_{r t}}\right)^{\frac{1}{1-\alpha}} .
$$

14 In the case that countries are fully open, the country technology capital stocks are indeterminate.

15 In our companion paper, we consider examples where some countries are on corners and do not accumulate technology capital. 
If $\phi>0$, then the ratio of foreign to domestic outputs in the two countries is given by

$$
\frac{Y_{r t}^{d}}{Y_{u t}^{d}}=\sigma_{r t}^{\frac{1}{\phi}}\left(\frac{1-\sigma_{u t}^{1 / \phi}}{1-\sigma_{r t}^{1 / \phi}}\right), \quad \frac{Y_{u t}^{f}}{Y_{r t}^{f}}=\sigma_{u t}^{\frac{1}{\phi}}\left(\frac{1-\sigma_{r t}^{1 / \phi}}{1-\sigma_{u t}^{1 / \phi}}\right),
$$

and the ratio of labor productivities is given by

$$
\frac{Y_{u t} / L_{u t}}{Y_{r t} / L_{r t}}=\left(\frac{\left(1-\sigma_{u t}^{1 / \phi}\right) A_{u t}^{1 / \phi} N_{u t}}{\left(1-\sigma_{r t}^{1 / \phi}\right) A_{r t}^{1 / \phi} N_{r t}}\right)^{\frac{\phi}{(1-\alpha)(1-\phi)}}
$$

which depends on the relative degrees of openness, the relative TFPs, and the relative populations. The more closed the country is, the higher is its TFP, and the more populous it is, the higher is its labor productivity relative to the other country.

Proof. The first-order conditions for the planner's problem, assuming no uncertainty, are given as follows:

$$
\begin{aligned}
& \mu_{t}=\lambda \frac{N_{u t}}{C_{u t}} \\
& \mu_{t}=(1-\lambda) \frac{N_{r t}}{C_{r t}} \\
& \mu_{t}(1-\alpha)(1-\phi) \frac{Y_{u t}^{d}}{L_{u t}^{d}}=\frac{\lambda \psi N_{u t}}{N_{u t}-L_{u t}} \\
& \mu_{t}(1-\alpha)(1-\phi) \frac{Y_{u t}^{f}}{L_{u t}^{f}}=\frac{\lambda \psi N_{u t}}{N_{u t}-L_{u t}} \\
& \mu_{t}(1-\alpha)(1-\phi) \frac{Y_{r t}^{d}}{L_{r t}^{d}}=\frac{(1-\lambda) \psi N_{r t}}{N_{r t}-L_{r t}} \\
& \mu_{t}(1-\alpha)(1-\phi) \frac{Y_{r t}^{f}}{L_{r t}^{f}}=\frac{(1-\lambda) \psi N_{r t}}{N_{r t}-L_{r t}} \\
& \mu_{t}=\beta \mu_{t+1}\left[1-\delta+\alpha(1-\phi) Y_{u, t+1}^{d} / K_{u, t+1}^{d}\right] \\
& \mu_{t}=\beta \mu_{t+1}\left[1-\delta+\alpha(1-\phi) Y_{u, t+1}^{f} / K_{u, t+1}^{f}\right] \\
& \mu_{t}=\beta \mu_{t+1}\left[1-\delta+\alpha(1-\phi) Y_{r, t+1}^{d} / K_{r, t+1}^{d}\right]
\end{aligned}
$$




$$
\begin{aligned}
& \mu_{t}=\beta \mu_{t+1}\left[1-\delta+\alpha(1-\phi) Y_{r, t+1}^{f} / K_{r, t+1}^{f}\right] \\
& \mu_{t}=\beta \mu_{t+1}\left[1-\delta+\phi\left(Y_{u, t+1}^{d}+Y_{r, t+1}^{d}\right) / M_{t+1}^{d}\right] \\
& \mu_{t}=\beta \mu_{t+1}\left[1-\delta+\phi\left(Y_{r, t+1}^{f}+Y_{u, t+1}^{f}\right) / M_{t+1}^{f}\right]
\end{aligned}
$$

for $t \geq 0$, where $\mu_{t}$ is the multiplier on the global resource constraint.

Capital-output ratios are equated within and across countries, and labor productivities are equated within countries. The capital-output ratios are equal to

$$
\kappa_{t}=\frac{\beta \alpha(1-\phi)}{c_{u t} / c_{u, t-1}-\beta(1-\delta)}
$$

where $c_{u t}=C_{u t} / N_{u t}$. Since labor productivities are equated within countries, it follows that

$$
\begin{aligned}
\frac{Y_{u t}^{f}}{Y_{u t}^{d}} & =\sigma_{u t}\left(\frac{M_{t}^{f}}{M_{t}^{d}}\right)^{\phi}\left(\frac{K_{u t}^{f}}{K_{u t}^{d}}\right)^{\alpha(1-\phi)}\left(\frac{L_{u t}^{f}}{L_{u t}^{d}}\right)^{(1-\alpha)(1-\phi)} \\
& =\sigma_{u t}\left(\frac{M_{t}^{f}}{M_{t}^{d}}\right)^{\phi}\left(\frac{\kappa_{t} Y_{u t}^{f}}{\kappa_{t} Y_{u t}^{d}}\right)^{\alpha(1-\phi)}\left(\frac{Y_{u t}^{f}}{Y_{u t}^{d}}\right)^{(1-\alpha)(1-\phi)} \\
& =\sigma_{u t}^{\frac{1}{\phi}} M_{t}^{f} / M_{t}^{d}
\end{aligned}
$$

if both regions are investing a positive amount in technology capital. The ratio (C.3.1) tells us that the ratio of foreign to domestic production in the United States increases with the ratio of technology capital stocks and the degree of U.S. openness. Here, we used the fact that labor productivities are equated when substituting out the ratio of labor inputs, $L_{u t}^{f} / L_{u t}^{d}=Y_{u t}^{f} / Y_{u t}^{d}$.

The ratio of foreign to domestic output in the rest of world is found similarly and is given by

$$
\frac{Y_{r t}^{d}}{Y_{r t}^{f}}=\sigma_{r t}^{\frac{1}{\phi}} M_{t}^{d} / M_{t}^{f} .
$$


Again, it must be the case that $L_{r t}^{d} / L_{r t}^{f}=Y_{r t}^{d} / Y_{r t}^{f}$.

Next, we use the fact that returns to technology capital are equated across companies,

$$
\frac{Y_{u t}^{d}+Y_{r t}^{d}}{M_{t}^{d}}=\frac{Y_{r t}^{f}+Y_{u t}^{f}}{M_{t}^{f}} .
$$

Into (C.3.3), we substitute the expressions $(C .2 .1)$ and $K_{i j t}=\kappa_{t} Y_{i j t}$ and simplify to get

$$
\begin{gathered}
\left(M_{t}^{d}\right)^{\phi-1}\left\{A_{u t} N_{u t}^{\phi}\left(\left(Y_{u t}^{d}\right)^{\alpha}\left(L_{u t}^{d}\right)^{1-\alpha}\right)^{1-\phi}+\sigma_{r t} A_{r t} N_{r t}^{\phi}\left(\left(Y_{r t}^{d}\right)^{\alpha}\left(L_{r t}^{d}\right)^{1-\alpha}\right)^{1-\phi}\right\} \\
=\left(M_{t}^{f}\right)^{\phi-1}\left\{\sigma_{u t} A_{u t} N_{u t}^{\phi}\left(\left(Y_{u t}^{f}\right)^{\alpha}\left(L_{u t}^{f}\right)^{1-\alpha}\right)^{1-\phi}\right. \\
\left.+A_{r t} N_{r t}^{\phi}\left(\left(Y_{r t}^{f}\right)^{\alpha}\left(L_{r t}^{f}\right)^{1-\alpha}\right)^{1-\phi}\right\} .
\end{gathered}
$$

Several more substitutions are needed before we can write an expression for the ratio of foreign to domestic output in each country.

Next, we use (C.3.1) and (C.3.2) and the fact that the ratios of labor inputs have the same expressions to eliminate $Y_{u}^{f}, Y_{r}^{f}, L_{u}^{f}$, and $L_{r}^{f}$ in the right-hand side of $(C .3 .4)$. The result is

$$
\begin{aligned}
& A_{u t} N_{u t}^{\phi}\left(\left(Y_{u t}^{d}\right)^{\alpha}\left(L_{u t}^{d}\right)^{1-\alpha}\right)^{1-\phi}+\sigma_{r t} A_{r t} N_{r t}^{\phi}\left(\left(Y_{r t}^{d}\right)^{\alpha}\left(L_{r t}^{d}\right)^{1-\alpha}\right)^{1-\phi} \\
& =\sigma_{u t}^{\frac{1}{\phi}} A_{u t} N_{u t}^{\phi}\left(\left(Y_{u t}^{d}\right)^{\alpha}\left(L_{u t}^{d}\right)^{1-\alpha}\right)^{1-\phi}+\sigma_{r t}^{\frac{-(1-\phi)}{\phi}} A_{r t} N_{r t}^{\phi}\left(\left(Y_{r t}^{d}\right)^{\alpha}\left(L_{r t}^{d}\right)^{1-\alpha}\right)^{1-\phi}(C .3 .5
\end{aligned}
$$

Dividing all terms in $(C .3 .5)$ by $\left(\left(Y_{u t}^{d}\right)^{\alpha}\left(L_{u t}^{d}\right)^{1-\alpha}\right)^{1-\phi}$ and combining terms results in the following relation:

$$
A_{u t} N_{u t}^{\phi}\left(1-\sigma_{u t}^{\frac{1}{\phi}}\right)=\left(\sigma_{r t}^{\frac{-(1-\phi)}{\phi}}-\sigma_{r t}\right) A_{r t} N_{r t}^{\phi}\left(\left(Y_{r t}^{d} / Y_{u t}^{d}\right)^{\alpha}\left(L_{r t}^{d} / L_{u t}^{d}\right)^{1-\alpha}\right)^{1-\phi} .
$$

This gives us one equation in the two ratios we are deriving: $Y_{r t}^{d} / Y_{u t}^{d}$ and $L_{r t}^{d} / L_{u t}^{d}$.

A second equation relating these ratios comes from the production technologies in (C.2.1) and the fact that all nontechnology capital-output ratios are equated. Using these 
facts, we get

$$
\frac{Y_{r t}^{d}}{Y_{u t}^{d}}=\left(\frac{\sigma_{r t} A_{r t} N_{r t}^{\phi}}{A_{u t} N_{u t}^{\phi}}\left(\frac{L_{r t}^{d}}{L_{u t}^{d}}\right)^{(1-\alpha)(1-\phi)}\right)^{\frac{1}{1-\alpha(1-\phi)}}
$$

With (C.3.6) and (C.3.7), we now can write simple expressions for the ratios of outputs and labor inputs of U.S. companies abroad relative to home:

$$
\begin{aligned}
& \frac{Y_{r t}^{d}}{Y_{u t}^{d}}=\sigma_{r t}^{\frac{1}{\phi}}\left(\frac{1-\sigma_{u t}^{\frac{1}{\phi}}}{1-\sigma_{r t}^{\frac{1}{\phi}}}\right) \\
& \frac{L_{r t}^{d}}{L_{u t}^{d}}=\sigma_{r t}^{\frac{1}{\phi}}\left(\frac{1-\sigma_{u t}^{\frac{1}{\phi}}}{1-\sigma_{r t}^{\frac{1}{\phi}}}\right)^{\frac{1-\alpha(1-\phi)}{(1-\alpha)(1-\phi)}}\left(\frac{A_{u t} N_{u t}^{\phi}}{A_{r t} N_{r t}^{\phi}}\right)^{\frac{1}{(1-\alpha)(1-\phi)}}
\end{aligned}
$$

The same steps are followed to derive the analogous relations for $Y_{u t}^{f} / Y_{r t}^{f}$ and $L_{u t}^{f} / L_{r t}^{f}$.

Finally, we can use the ratios of outputs and hours in (C.3.8) and (C.3.9) to express the ratio of labor productivities:

$$
\begin{aligned}
\frac{Y_{u t} / L_{u t}}{Y_{r t} / L_{r t}} & =\frac{Y_{u t}^{d} / L_{u t}^{d}}{Y_{r t}^{d} / L_{r t}^{d}} \\
& =\left(\frac{1-\sigma_{u t}^{\frac{1}{\phi}}}{1-\sigma_{r t}^{\frac{1}{\phi}}}\right)^{\frac{\phi}{(1-\alpha)(1-\phi)}}\left(\frac{A_{u t} N_{u t}^{\phi}}{A_{r t} N_{r t}^{\phi}}\right)^{\frac{1}{(1-\alpha)(1-\phi)}} .
\end{aligned}
$$

If $\phi=0$, then $\sigma_{i t}^{1 / \phi}=0, N_{i t}^{\phi}=1$ and the ratio of labor productivities is equal to the ratio of TFPs raised to the power $1 /(1-\alpha)$. If $\phi>0$, then the relative productivities depend not only on the relative TFPs, but also on the relative degrees of openness and the relative populations.

Next, we report on the model's predictions for components of the U.S. net exports. 


\section{C.4. Net Exports}

In this section, we investigate the model's predictions as we change the relative TFPs, the relative population sizes, and the relative degrees of openness. We first consider perturbations around a steady state and derive analytical results, and then we run numerical simulations and report transition paths. In both, we demonstrate that the experiments look very different for cases with and without technology capital.

\section{C.4.1. Steady State Results}

The goal of this section is to derive analytical expressions for changes in U.S. net exports and net factor incomes relative to U.S. output as we change the rest-of-world TFP, population, and degree of openness. The main results are summarized in Proposition 2. After deriving the results, we consider cases with and without technology capital.

Proposition 2. Changes in the ratio of net exports to output are given by

$$
d\left(N X_{u} / Y_{u}\right)=-d\left(C_{u} / Y_{u}\right)-\delta d\left(M_{d} / Y_{u}\right)
$$

where the percentage change in the consumption share is equal to

$$
\begin{aligned}
\frac{d\left(C_{u} / Y_{u}\right)}{C_{u} / Y_{u}}=\{1 & \left.-\frac{\Delta_{u}}{C_{u}}+\frac{h_{u}}{h_{r}}\left(\frac{\Delta_{u}+C_{r}}{C_{u}}\right)\right\}^{-1} \\
& \cdot\left\{\left(\frac{\Delta_{u}}{C_{u}}\right) \frac{d N_{r}}{N_{r}}+\frac{1}{h_{r}}\left(\frac{\Delta_{u}+C_{r}}{C_{u}}\right)\left[\frac{d\left(Y_{r} / L_{r}\right)}{Y_{r} / L_{r}}-\frac{d\left(Y_{u} / L_{u}\right)}{Y_{u} / L_{u}}\right]\right\} C .
\end{aligned}
$$

and the changes in labor productivities equal to

$$
\begin{aligned}
& \frac{d\left(Y_{u} / L_{u}\right)}{Y_{u} / L_{u}}=\frac{1}{(1-\alpha)(1-\phi)}\left(\frac{\sigma_{r}^{\frac{1}{\phi}}}{1-\sigma_{r}^{\frac{1}{\phi}} \sigma_{u}^{\frac{1}{\phi}}}\right)\left(\frac{1-\sigma_{u}^{\frac{1}{\phi}}}{1-\sigma_{r}^{\frac{1}{\phi}}}\right) \frac{d \sigma_{r}}{\sigma_{r}} \\
& \frac{d\left(Y_{r} / L_{r}\right)}{Y_{r} / L_{r}}=\frac{1}{(1-\alpha)(1-\phi)}\left\{\left(\frac{-\sigma_{r}^{\frac{1}{\phi}} \sigma_{u}^{\frac{1}{\phi}}}{1-\sigma_{r}^{\frac{1}{\phi}} \sigma_{u}^{\frac{1}{\phi}}}\right) \frac{d \sigma_{r}}{\sigma_{r}}+\frac{d A_{r}}{A_{r}}+\phi \frac{d N_{r}}{N_{r}}\right\} .
\end{aligned}
$$


All variables and derivatives are evaluated at the steady state, $l_{i}=L_{i} / N_{i}$, and

$$
\begin{aligned}
\Delta_{u} & =(1-\delta \kappa-\delta \mu) Y_{r}-C_{r} \\
\kappa & =\beta \alpha(1-\phi) /(1-\beta(1-\delta)) \\
\mu & =\beta \phi /(1-\beta(1-\delta)) .
\end{aligned}
$$

The change in $M_{d} / Y_{u}$ is

$$
d\left(M_{d} / Y_{u}\right)=\frac{1}{1-\sigma_{u}^{1 / \phi} \sigma_{r}^{1 / \phi}}\left(\frac{\sigma_{r}^{1 / \phi}}{\phi\left(1-\sigma_{r}^{1 / \phi}\right)} \frac{M_{u}}{Y_{u}} \frac{d \sigma_{r}}{\sigma_{r}}-\sigma_{u}^{1 / \phi} \frac{M_{r}}{Y_{r}} d\left(Y_{r} / Y_{u}\right)\right)
$$

where $M_{u}=M_{d}+\sigma_{u}^{1 / \phi} M_{f}, M_{r}=M_{f}+\sigma_{r}^{1 / \phi} M_{d}$, and

$$
\begin{aligned}
\frac{d\left(Y_{r} / Y_{u}\right)}{Y_{r} / Y_{u}}= & \left\{1-\frac{\Delta_{u}}{C_{u}}+\frac{h_{u}}{h_{r}}\left(\frac{\Delta_{u}+C_{r}}{C_{u}}\right)\right\}^{-1} \\
& \cdot\left\{\left(1+\frac{h_{u}}{h_{r}} \frac{C_{r}}{C_{u}}\right) \frac{d N_{r}}{N_{r}}+\frac{1}{h_{r}}\left(1+\frac{C_{r}}{C_{u}}\right)\left[\frac{d\left(Y_{r} / L_{r}\right)}{Y_{r} / L_{r}}-\frac{d\left(Y_{u} / L_{u}\right)}{Y_{u} / L_{u}}\right]\right\}(. C .
\end{aligned}
$$

Proof. In a steady state, the ratio of net exports to output for country $u$ is given by

$$
\begin{aligned}
\frac{N X_{u}}{Y_{u}} & =\left(Y_{u}-X_{d}-X_{u}-C_{u}\right) / Y_{u} \\
& =1-\delta M_{d} / Y_{u}-\delta \kappa-C_{u} / Y_{u},
\end{aligned}
$$

where $\kappa=K_{i j} / Y_{i j}$ is equal to (C.4.6) above. Fully differentiating this ratio, we get

$$
d\left(N X_{u} / Y_{u}\right)=-\delta d\left(M_{d} / Y_{u}\right)-d\left(C_{u} / Y_{u}\right)
$$

Note that the variations we consider do not affect $\kappa$.

Since both derivatives in (C.4.10) depend on derivatives of relative productivities, we derive them first. Using (C.3.10), simple algebra yields

$$
\frac{d\left(Y_{r} / L_{r}\right)}{Y_{r} / L_{r}}=-\frac{1}{(1-\alpha)(1-\phi)}\left\{\frac{\sigma_{r}^{1 / \phi}}{1-\sigma_{r}^{1 / \phi}} \frac{d \sigma_{r}}{\sigma_{r}}-\frac{d A_{r}}{A_{r}}-\phi \frac{d N_{r}}{N_{r}}\right\}+\frac{d\left(Y_{u} / L_{u}\right)}{Y_{u} / L_{u}}
$$


where it is implicitly assumed that variation is due only to changes in $N_{r}, A_{r}$, or $\sigma_{r}$. A second relation involving $d\left(Y_{r} / L_{r}\right)$ and $d\left(Y_{u} / L_{u}\right)$ is derived using the fact that the return on U.S. technology capital, $\phi\left(Y_{u}^{d}+Y_{r}^{d}\right) / M^{d}$, does not depend on the magnitudes of $A_{r}$, $N_{r}$, or $\sigma_{r}$, so that

$$
\begin{aligned}
\frac{d M_{d}}{M_{d}} & =\left(\frac{Y_{u}^{d}}{Y_{u}^{d}+Y_{r}^{d}}\right) \frac{d Y_{u}^{d}}{Y_{u}^{d}}+\left(\frac{Y_{r}^{d}}{Y_{u}^{d}+Y_{r}^{d}}\right) \frac{d Y_{r d}}{Y_{r d}} \\
& =\left(\frac{Y_{u}^{d}}{Y_{u}^{d}+Y_{d}^{r}}\right)\left(\frac{d M^{d}}{M^{d}}-\frac{(1-\alpha)(1-\phi)}{\phi} \frac{d\left(Y_{u} / L_{u}\right)}{Y_{u} / L_{u}}\right) \\
& +\left(\frac{Y_{r}^{d}}{Y_{u}^{d}+Y_{r}^{d}}\right)\left(\frac{d M^{d}}{M^{d}}-\frac{(1-\alpha)(1-\phi)}{\phi} \frac{d\left(Y_{r} / L_{r}\right)}{Y_{r} / L_{r}}\right. \\
& \left.+\frac{1}{\phi} \frac{d \sigma_{r}}{\sigma_{r}}+\frac{1}{\phi} \frac{d A_{r}}{A_{r}}+\frac{d N_{r}}{N_{r}}\right) .
\end{aligned}
$$

The second equation in (C.4.12) is derived by fully differentiating the equations in (C.2.1) and using the fact that labor productivities are equated within countries and capital-output ratios are equated across countries. The term $d M_{d} / M_{d}$ cancels on both sides of equation (C.4.12), and after simplifying, we are left with

$$
\frac{Y_{u}^{d}}{Y_{r}^{d}} \frac{d\left(Y_{u} / L_{u}\right)}{Y_{u} / L_{u}}+\frac{d\left(Y_{r} / L_{r}\right)}{Y_{r} / L_{r}}=\frac{1}{(1-\alpha)(1-\phi)}\left\{\frac{d \sigma_{r}}{\sigma_{r}}+\frac{d A_{r}}{A_{r}}+\phi \frac{d N_{r}}{N_{r}}\right\} .
$$

Solving (C.4.11) and (C.4.13) for $d\left(L_{u} / Y_{u}\right)$ and $d\left(L_{r} / Y_{r}\right)$ yields the expressions $(C .4 .3)$ and (C.4.4) given in the statement of the proposition.

The next step is to use the intratemporal conditions and the global resource constraint to jointly determine $d L_{u}, d L_{r}$, and $d C_{u} / Y_{u}$. In particular, we fully differentiate the following three equations:

$$
\begin{aligned}
& \frac{N_{u}-L_{u}}{N_{r}-L_{r}}=\frac{\lambda}{1-\lambda}\left(\frac{N_{u}}{N_{r}}\right)\left(\frac{Y_{r} / L_{r}}{Y_{u} / L_{u}}\right) \\
& \frac{C_{u}}{Y_{u}}=\frac{(1-\alpha)(1-\phi)}{\psi}\left(\frac{N_{u}-L_{u}}{L_{u}}\right) \\
& \frac{C_{u}}{Y_{u}}\left(1+\frac{(1-\lambda) N_{r}}{\lambda N_{u}}\right)=(1-\delta \kappa-\delta \mu)\left(1+\frac{L_{r}}{L_{u}} \frac{Y_{r} / L_{r}}{Y_{u} / L_{u}}\right),
\end{aligned}
$$


with the derivative of the ratio of productivities given as above. In writing the last equations, we made two simple substitutions for $C_{r} / Y_{r}$ and $Y_{r} / Y_{u}$ so as to make the algebra more manageable.

We spare the reader details of the tedious algebra but describe the exact steps to get the expression (C.4.2). We first replace $C_{u} / Y_{u}$ in (C.4.16) using $(C .4 .15)$, and then we fully differentiate $(C .4 .14)$ and $(C .4 .16)$. Once differentiated, the two equations can be simplified and written as two equations with unknowns $d L_{u}$ and $d L_{r}$ that are written in terms of $d N_{r}, d\left(Y_{r} / L_{r}\right)$, and $d\left(Y_{u} / L_{u}\right)$. As shown above, derivatives of labor productivities can be written in terms of changes of exogenous variables. See, in particular, equations (C.4.3) and (C.4.4). Thus, the changes in hours found by differentiating $(C .4 .14)$ and $(C .4 .16)$ can be written explicitly in terms of changes of exogenous variables, namely $d N_{r}$, $d A_{r}$, and $d \sigma_{r}$. The final step is to differentiate (C.4.15), thus expressing $d C_{u} / Y_{u}$ in terms of $d L_{u}$. Substituting in the expression for $d L_{u}$, we have (C.4.2).

Next, we need $M_{d} / Y_{u}$. Since it is easier to work with effective technology capital stocks, we define $M_{u}=M_{d}+\sigma_{u}^{1 / \phi} M_{f}$ and $M_{r}=M_{f}+\sigma_{r}^{1 / \phi} M_{d}$ as the effective stocks used in the United States and the ROW, respectively. Using the production technologies, we can write total outputs in terms of $M_{u}$ and $M_{r}$ as follows:

$$
\begin{gathered}
Y_{u}=A_{u}\left(N_{u} M_{u}\right)^{\phi} K_{u}^{\alpha(1-\phi)} L_{u}^{(1-\alpha)(1-\phi)} \\
Y_{r}=A_{r}\left(N_{r} M_{r}\right)^{\phi} K_{r}^{\alpha(1-\phi)} L_{r}^{(1-\alpha)(1-\phi)} .
\end{gathered}
$$

If we replace $K_{i}$ with $\kappa Y_{i}$ and simplify, we get

$$
\begin{aligned}
& \frac{M_{u}}{Y_{u}}=A_{u}^{-1 / \phi} N_{u}^{-1} \kappa^{\frac{-\alpha(1-\phi)}{\phi}}\left(Y_{u} / L_{u}\right)^{\frac{(1-\alpha)(1-\phi)}{\phi}} \\
& \frac{M_{r}}{Y_{r}}=A_{r}^{-1 / \phi} N_{r}^{-1} \kappa^{\frac{-\alpha(1-\phi)}{\phi}}\left(Y_{r} / L_{r}\right)^{\frac{(1-\alpha)(1-\phi)}{\phi}} .
\end{aligned}
$$

Next, express $M_{d} / Y_{u}$ in terms of $M_{u} / Y_{u}$ and $M_{r} / Y_{r}$ :

$$
\frac{M_{d}}{Y_{u}}=\frac{1}{1-\sigma_{u}^{1 / \phi} \sigma_{r}^{1 / \phi}}\left(\frac{M_{u}}{Y_{u}}-\sigma_{u}^{\frac{1}{\phi}} \frac{M_{r}}{Y_{r}} \frac{Y_{r}}{Y_{u}}\right) .
$$


Differentiating this, we get

$$
\begin{aligned}
\frac{d\left(M_{d} / Y_{u}\right)}{M_{d} / Y_{u}}=\frac{1}{1-\sigma_{u}^{1 / \phi} \sigma_{r}^{1 / \phi}}( & \left.\frac{M_{u}}{M_{d}} \frac{d\left(M_{u} / Y_{u}\right)}{M_{u} / Y_{u}}-\sigma_{u}^{\frac{1}{\phi}} \frac{M_{r}}{M_{d}}\left\{\frac{d\left(M_{r} / Y_{r}\right)}{M_{r} / Y_{r}}+\frac{d\left(Y_{r} / Y_{u}\right)}{Y_{r} / Y_{u}}\right\}\right) \\
& +\frac{\sigma_{u}^{\frac{1}{\phi}} \sigma_{r}^{\frac{1}{\phi}}}{\phi\left(1-\sigma_{u}^{\frac{1}{\phi}} \sigma_{r}^{\frac{1}{\phi}}\right)} \frac{d \sigma_{r}}{\sigma_{r}}
\end{aligned}
$$

where $M_{u}=M_{d}+\sigma_{u}^{1 / \phi} M_{f}$ and $M_{r}=M_{f}+\sigma_{r}^{1 / \phi} M_{d}$.

Equation (C.4.19) requires the derivatives of the technology capital stocks relative to output shown in (C.4.17) and (C.4.18):

$$
\begin{aligned}
& \frac{d\left(M_{u} / Y_{u}\right)}{M_{u} / Y_{u}}=\frac{(1-\alpha)(1-\phi)}{\phi} \frac{d\left(Y_{u} / L_{u}\right)}{Y_{u} / L_{u}} \\
& \frac{d\left(M_{r} / Y_{r}\right)}{M_{r} / Y_{r}}=\frac{(1-\alpha)(1-\phi)}{\phi} \frac{d\left(Y_{r} / L_{r}\right)}{Y_{r} / L_{r}}-\frac{1}{\phi} \frac{d A_{r}}{A_{r}}-\frac{d N_{r}}{N_{r}},
\end{aligned}
$$

which in turn requires knowing $d\left(Y_{u} / L_{u}\right), d\left(Y_{r} / L_{r}\right)$, and $d\left(Y_{r} / Y_{u}\right)$. Derivatives for the labor productivities were derived above and are given in equations (C.4.3) and (C.4.4). Substituting for these in (C.4.19) and simplifying yields

$$
d\left(M_{d} / Y_{u}\right)=\frac{1}{1-\sigma_{u}^{1 / \phi} \sigma_{r}^{1 / \phi}}\left(\frac{\sigma_{r}^{1 / \phi}}{\phi\left(1-\sigma_{r}^{1 / \phi}\right)} \frac{M_{u}}{Y_{u}} \frac{d \sigma_{r}}{\sigma_{r}}-\sigma_{u}^{1 / \phi} \frac{M_{r}}{Y_{r}} d\left(Y_{r} / Y_{u}\right)\right)
$$

where

$$
\begin{aligned}
& \frac{d\left(Y_{r} / Y_{u}\right)}{Y_{r} / Y_{u}}=\frac{C_{u}}{\Delta_{u}}\left(\frac{d\left(C_{u} / Y_{u}\right)}{C_{u} / Y_{u}}\right)+\frac{C_{r}}{\Delta_{u}}\left(\frac{d\left(C_{r} / Y_{r}\right)}{C_{r} / Y_{r}}\right) \\
& \frac{d\left(C_{r} / Y_{r}\right)}{C_{r} / Y_{r}}=\frac{h_{u}}{h_{r}}\left(\frac{d\left(C_{u} / Y_{u}\right)}{C_{u} / Y_{u}}\right)-\frac{1}{h_{r}}\left[\frac{d Y_{r} / L_{r}}{Y_{r} / L_{r}}-\frac{d Y_{u} / L_{u}}{Y_{u} / L_{u}}\right] .
\end{aligned}
$$

The derivative for the relative outputs was found by differentiating the global resource constraint,

$$
\frac{C_{u}}{Y_{u}}+\frac{C_{r}}{Y_{r}} \frac{Y_{r}}{Y_{u}}=(1-\delta \kappa-\delta \mu)\left(1+\frac{Y_{r}}{Y_{u}}\right)
$$


which yields (C.4.22) as a function of the derivatives of the two consumption shares, $C_{u} / Y_{u}$ and $C_{r} / Y_{r}$. The rest of world consumption share is found by differentiating:

$$
\frac{C_{r}}{Y_{r}}=\frac{(1-\alpha)(1-\phi)}{\psi}\left(\frac{N_{r}-L_{r}}{L_{r}}\right)
$$

and using the solution to $d L_{r}$ found above.

The expression for $d\left(Y_{r} / Y_{u}\right)$ can be further simplified by replacing $d\left(C_{u} / Y_{u}\right)$ in $(C .4 .22)$ and (C.4.23) with (C.4.2).

We are now ready to compare changes in the ratio of net exports share in economies with technology capital to changes in economies without technology capital.

If $\phi=0$, then productivity in the economy that does not experience any changes in TFP, population, or openness does not change, that is, $d\left(Y_{u} / L_{u}\right)=0$. In ROW, the only thing that matters is TFP:

$$
\frac{d\left(Y_{r} / L_{r}\right)}{Y_{r} / L_{r}}=\frac{1}{1-\alpha} \frac{d A_{r}}{A_{r}} .
$$

As an example, assume that $\alpha=.3$. Then, a 1 percent increase in ROW TFP leads to a 1.43 percent increase in ROW productivity. But there are no spillovers to productivity in country $u$, the United States.

When $\phi=0$, a rise in TFP in ROW impacts net exports in the United States only through changes in consumption because neither country invests in technology capital. In this case,

$$
\begin{aligned}
\left.d\left(N X_{u} / Y_{u}\right)\right|_{\phi=0}= & -\left\{1-\frac{\Delta_{u}}{C_{u}}+\frac{h_{u}}{h_{r}}\left(\frac{\Delta_{u}+C_{r}}{C_{u}}\right)\right\}^{-1} \\
& \cdot\left\{\left(\frac{\Delta_{u}}{Y_{u}}\right) \frac{d N_{r}}{N_{r}}+\frac{1}{h_{r}(1-\alpha)}\left(\frac{\Delta_{u}+C_{r}}{Y_{u}}\right) \frac{d A_{r}}{A_{r}}\right\},
\end{aligned}
$$

where, in this case with $\phi=0, \Delta_{u}=N X_{r}=-N X_{u}$. 
If we choose empirically plausible parameters, the steady state level of $\Delta_{u}$ would be close to zero. With this further simplification, the ratio of net exports to output in the standard model without technology capital is given by

$$
\left.d\left(N X_{u} / Y_{u}\right)\right|_{\phi=0, \Delta_{u}=0}=-\left\{1+\frac{h_{u}}{h_{r}} \frac{C_{r}}{C_{u}}\right\}^{-1}\left(\frac{C_{r}}{h_{r}(1-\alpha) Y_{u}}\right) \frac{d A_{r}}{A_{r}}
$$

Compare (C.4.25) with the same expression for the case with $\phi>0$ and $\Delta_{u}=0$, which is given by

$$
\begin{aligned}
\left.d\left(N X_{u} / Y_{u}\right)\right|_{\phi>0, \Delta_{u}=0}=-\left\{1+\frac{h_{u}}{h_{r}} \frac{C_{r}}{C_{u}}\right\}^{-1}\left(\frac{C_{r}}{h_{r}(1-\alpha) Y_{u}}\right) & \left\{\frac{1}{1-\phi} \frac{d A_{r}}{A_{r}}\right. \\
& +\frac{\phi}{1-\phi} \frac{d N_{r}}{N_{r}} \\
& \left.-\frac{\sigma_{r}^{1 / \phi}}{\left(1-\sigma_{r}^{1 / \phi}\right)} \frac{1}{1-\phi} \frac{d \sigma_{r}}{\sigma_{r}}\right\} \\
& -\delta d\left(M_{d} / Y_{u}\right) .
\end{aligned}
$$

We laid out equation (C.4.26) in such a way as to make the comparison with (C.4.25) simple. These relations share the first term, although the impact of TFP is larger when $\phi>0$ because $1 /(1-\phi)>1$. In the case of $\phi=0$, there are no additional effects due to $d N_{r}$ or $d \sigma_{r}$. As we show next, this abstraction can be quantitatively important.

We now consider a simple numerical exercise to illustrate that adding $\phi>0$ can have a quantitatively important impact on the productivities, consumption shares, and net exports. In Table C.1, we report parameter values that we use in this simple model for this exercise. These are not the same parameters used in our paper, since the model of this section is a stripped-down version of the model in the main paper.

We choose $\beta=0.96$, since we abstracted from trend growth. This implies an annual interest rate of around 4 percent. We choose the leisure weight so that time at work is 
between 25 percent and 30 percent of total time. We set income shares so that the split of nontechnology capital income is 30/70 for capital and labor. The common depreciation rate is set at 5 percent. The ratio of ROW population to the U.S. population is 8. Regardless of $\phi$ we set initial debt equal to 0 . This implies $\lambda=.79$ in both the model with and the model without technology capital. The relative technology levels are set so that U.S. GDP is equal to 32 percent of world GDP. Finally, in the case with technology capital, we need to specify openness parameters. For the steady state calculations we use .75 for both.

Let us start with the model with technology capital and $\phi>0$. With the parameters set as in Table C.1, $h_{u}$ and $h_{r}$ are both around 0.287 , the consumption ratios are both around 0.81, and $C_{r} / C_{u}=2.13$. The parameters also imply that the residual $\Delta_{u}$ is approximately equal to 0 .

Using these values in the formulas above, we consider changes in the three exogenous ROW variables: $A_{r}, N_{r}$, and $\sigma_{r}$. The U.S. labor productivity does not change with either $A_{r}$ or $N_{r}$, but ROW labor productivity does. The formulas yield $d\left(Y_{r} / L_{r}\right) /\left(Y_{r} / L_{r}\right)=$ $4.21 d A_{r}$ and $d\left(Y_{r} / L_{r}\right) /\left(Y_{r} / L_{r}\right)=.0134 d N_{r}$. The openness parameter affects both labor productivities, with the largest impact on U.S. productivity: $d\left(Y_{u} / L_{u}\right) /\left(Y_{u} / L_{u}\right)=$ $.0336 d \sigma_{r}$ and $d\left(Y_{r} / L_{r}\right) /\left(Y_{r} / L_{r}\right)=-.0006 d \sigma_{r}$.

In terms of changes in the U.S. consumption share, we find $d\left(C_{u} / Y_{u}\right) /\left(C_{u} / Y_{u}\right)=$ $-9.98 d A_{r}, d\left(C_{u} / Y_{u}\right) /\left(C_{u} / Y_{u}\right)=.0318 d N_{r}$, and $d\left(C_{u} / Y_{u}\right) /\left(C_{u} / Y_{u}\right)=-.081 d \sigma_{r}$. These effects are much larger than those on the technology capital investment: $d\left(\delta M_{d} / Y_{u}\right)=$ $.02 d A_{r}, d\left(\delta M_{d} / Y_{u}\right)=-.0002 d N_{r}$, and $d\left(\delta M_{d} / Y_{u}\right)=.013 d \sigma_{r}$. Thus, most of the change in the U.S. net exports share comes from the change in the U.S. consumption share term in $(C .4 .1)$.

Adding the derivatives of the consumption share and the investment share together yields the following results for the net exports share: $d\left(N X_{u} / Y_{u}\right)=-8.10 d A_{r}, d\left(N X_{u} / Y_{u}\right)$ 
$=-.026 d N_{r}$, and $d\left(N X_{u} / Y_{u}\right)=.053 d \sigma_{r}$. With $A_{r}=.365$, a 1 percent change in the ROW TFP implies a drop in net exports from 0.13 percent of output to -3 percent of output.

With $N_{r}=8$, a 1 percent increase in the ROW population implies a drop in net exports from 0.13 percent of output to roughly -.2 percent of output. With a 20 percent increase in the ROW population, which is more empirically plausible for the post-World War II period, there is a drop in net exports from 0.13 percent to about -4 percent of output. With $\sigma_{r}=.75$, a 1 percent increase in the ROW degree of openness implies an increase in net exports from 0.13 percent of output to 0.17 percent of output.

Now, suppose that technology capital is not included in the model and $\phi=0$. With the parameters set as in Table C.1, $h_{u}$ and $h_{r}$ are both around 0.295 , the consumption ratios are both around 0.836 , and $C_{r} / C_{u}=2.13$. In this case, the parameters again imply that the residual $\Delta_{u}$ is approximately equal to 0 . Using the formula in (C.4.25), we get $d\left(N X_{u} / Y_{u}\right)=-6.96 d A_{r}$. In the case with $\phi=.07$, we found $d\left(N X_{u} / Y_{u}\right)=-8.10 d A_{r}$, which implies that technology amplifies the impact of changes in TFP.

\section{C.4.2. Transition Results}

In this section, we analyze equilibrium paths for the stripped-down model economy that we analyzed above.

The main point of this section, as in the earlier section, is to demonstrate that adding technology capital leads to very different predictions. Here, we focus on equilibrium paths. Since changes in population and TFP have different impacts on equilibrium paths, we consider changing each, one at a time. The time series of these inputs are displayed in Figures C.1 and C.2.

The experiments use the same constants as in Table C.1 and initial conditions from Tables C.2 and C.3. In Table C.2, we list the initial capital stocks for experiments with 
fixed degrees of openness. In Table C.3, we list the initial capital stocks for an experiment with increasing degrees of openness.

If there are no changes in any exogenous parameters, the capital stocks remain at the levels shown in Tables C.2 and C.3. If households do expect changes in the exogenous parameters and $B_{0}$ is set equal to zero, then the equilibrium paths display initial jumps or declines in investments in anticipation of shifting production. For this reason, we adjusted the initial debt level in each experiment so that investment would adjust smoothly. These necessary adjustments are reported in Tables C.2 and C.3. If we instead hold $B_{0}=0$, the model predicts initial adjustments in investments, but the equilibrium paths that we display would have exactly the same patterns after year $1 .{ }^{16}$

\section{Increased ROW Population}

We first consider the model's time series predictions when the population of the rest of world increases relative to that of the United States, as shown in Figure C.1. The main findings for this experiment are shown in Figures C.3-C.6.

In Figure C.1, we display the time series of the ROW population $N_{r t}$ for our first experiment, with $N_{u t}$ set equal to one in all periods. The ROW population starts at 8, rises almost 20 percent, and then returns. Here, we assume that TFPs are fixed. ${ }^{17}$

As we discussed in the main paper, the path of the relative size of countries is an important determinant of the path of net exports. In Figure C.3, we show the actual U.S. net exports relative to GDP along with model predictions in the case with technology capital included and in the case without. We plot the U.S. data to show that the model with technology capital can generate a dramatic drop in net exports relative to GDP, such

16 The computer codes at http://www.minneapolisfed.org offer the user the choice of adjusting or not adjusting the debt level.

17 We also ran cases for permanent increases after 2003. The results over the period 1960-2000 are so close that we do not report them here. Interested readers can see results of these experiments at our website. 
as that experienced recently in the United States. To emphasize the difference between the models with and without technology capital, we show both in Figure C.3. If there is no technology capital, the net exports share remains at about 1 percent until the late 1990s and then declines to roughly -1 percent of output.

If there is no technology capital, the stripped-down model predicts an increase in investment abroad, which is becoming more populous, and then a shift back when the rest-of-world population reverts to its balanced growth path. ${ }^{18}$ Let $\mathcal{A}=A^{1 /(1-\alpha)}$. We can write net exports in the United States and ROW relative to size as follows:

$$
\begin{aligned}
\frac{N X_{u t}}{\mathcal{A}_{u t} N_{u t}} & =\frac{Y_{u t}-C_{u t}-X_{u t}}{\mathcal{A}_{u t} N_{u t}} \\
-\frac{N X_{u t}}{\mathcal{A}_{r t} N_{r t}} & =\frac{Y_{r t}-C_{r t}-X_{r t}}{\mathcal{A}_{r t} N_{r t}},
\end{aligned}
$$

where we have used the fact that $N X_{r t}=-N X_{u t}$. If we sum these, we get

$$
\begin{aligned}
& \left(\frac{1}{\mathcal{A}_{u t} N_{u t}}+\frac{1}{\mathcal{A}_{r t} N_{r t}}\right) N X_{u t} \\
& \quad=\left(\frac{Y_{u t}}{\mathcal{A}_{u} N_{u t}}-\frac{Y_{r t}}{\mathcal{A}_{r} N_{r t}}\right)-\left(\frac{C_{u t}}{\mathcal{A}_{u} N_{u t}}-\frac{C_{r t}}{\mathcal{A}_{r} N_{r t}}\right)-\left(\frac{X_{u t}}{\mathcal{A}_{u} N_{u t}}-\frac{X_{r t}}{\mathcal{A}_{r} N_{r t}}\right) \\
& \quad=-\left(\frac{X_{u t}}{\mathcal{A}_{u} N_{u t}}-\frac{X_{r t}}{\mathcal{A}_{r} N_{r t}}\right), \quad \text { if } \phi=0 .
\end{aligned}
$$

The equality in (C.4.27) only holds when $\phi=0$ and follows from the fact that the parameters in Tables C.1 and C.2 imply that the ratio of per capita consumption in the United States relative to the ROW is equal to $\mathcal{A}_{u} / \mathcal{A}_{r} \cdot{ }^{19}$ Since relative labor productivities are also equal to this ratio (as seen in $(C .3 .10)$ ), it follows from the intratemporal conditions that outputs per effective person, $Y_{i t} / \mathcal{A}_{i} N_{i t}$, are also equal. Thus, in the case of $\phi=0$,

18 If $B_{0}$ is set equal to zero, then there is an initial jump in U.S. net exports and an initial drop in U.S. investment.

19 The allocations for the decentralized economy with $B_{0}=-.081$ are the same as the planner's problem with $\lambda=.79$. The ratios of per capita consumptions in both cases are equal to 3.76. 
the only borrowing and lending that goes on (assuming no initial jumps) is done so that capital-output ratios can be equalized.

In Figures C.4-C.6, we show the paths of the consumption shares, labor productivities, and per capita GDPs for the models with and without technology capital. In all three, the paths for the two countries lie on top of each other when technology capital is excluded $(\phi=0)$. When the model includes technology capital $(\phi>0)$, the patterns for the United States and ROW are completely different. There are two reasons for this. The first reason is that GDP does not include all output produced in a country. True output includes investment in technology capital. Therefore, although capital-output ratios are equated, both within countries (across domestic and foreign firms) and across countries, these relations do not imply that measured capital to GDP ratios are equated.

A second reason for the different patterns in equilibrium paths for U.S. and ROW series is that size has a positive scale effect on GDP per capita and productivity. This scale effect arises because of the fact that technology capital can be used simultaneously at multiple locations and the measure of locations is proportional to a country's population. As the ROW population increases, its output increases by more than the rise in population. With greater world production, per capita consumptions rise in both countries, but the share of consumption in GDP rises in the United States as more production is being done abroad and falls in the ROW where GDP is rising. This is shown in Figure C.4.

Figure C.5 shows that the ROW labor productivity increases relative to U.S. labor productivity as $N_{r t} / N_{u t}$ increases, which is consistent with $(C .3 .10)$. Because relative per capita hours are changing, we also predict deviations in per capita GDPs, with the ROW increasing relative to the United States.

In Figures C.7-C.8, we show how the prediction for the U.S. trade deficit changes if we allow for different patterns of openness. In Figure C.7, we use the same series as in the 
main paper. Figure C. 8 shows the result and compares it to the case with the degrees of openness fixed. In the case of the trade deficit, the main difference is that the predicted decline in the net export share is not as large if we assume that countries are opening to FDI as the ROW population increases.

Here, we are working with a stripped-down version of our model with technology capital, but there are some lessons that are common in the two exercises. First, with an empirically plausible rise in the population of the ROW, the model generates a large and empirically plausible decline in net exports relative to GDP, which is much larger than standard theory predicts. Second, the model generates a plausible increase in the U.S. consumption share of GDP and a plausible decline in the U.S. share of world GDP.

\section{Increased ROW TFP}

We turn next to the experiment of increasing ROW size by increasing total factor productivity. In Figure C.2, we display the time series of the ROW total factor productivity $A_{r t}$ relative to $A_{r 0}$. We chose an increase of 1.2 percent for ROW TFP in order to generate an empirically plausible decline in the share of net exports in GDP. As before, we compare the predictions of the models with and without technology capital. The results are shown in Figures C.9-C.12.

In Figure C.9, we plot the ratio of U.S. net exports relative to GDP for the strippeddown model with and without technology. For the sake of comparison, we also plot the actual U.S. share. Interestingly, the pattern looks very different from that of Figure C.3, which shows the change in U.S. net exports in the case of higher ROW population. The primary reason for the difference is that GDP rather than output is in the denominator. Recall that our formulas above used output rather than GDP, which is equal to output less investment in technology capital. We did this to make the analytical results more tractable. 
In Figures C.10-C.12, we show the consumption shares, labor productivities, and per capita GDP for the models with and without technology capital. As we demonstrated earlier, changes in the endogenous variables are similar in the two models, except that there is some amplification of the impact in the case of the model with technology capital, since the term $1 /(1-\phi)$, which multiplies $A_{r}$, is greater than 1 . 
TaBle C.1. Parameter Values for Steady State Analysis

IN THE STRIPPED-Down Model

\begin{tabular}{lcr}
\hline PARAMETERS & EXPRESSION & VALUE \\
\hline Common parameters & $\beta$ & .96 \\
Discount factor & $\psi$ & 2 \\
Leisure weight in utility & $\alpha$ & .3 \\
Capital share of other income & $\delta$ & .05 \\
Depreciation rate & $N_{r} / N_{u}$ & 8 \\
Relative populations & $B_{0}$ & 0 \\
Initial debt & & .07 \\
With technology capital & $\phi$ & .365 \\
Technology capital share & $A_{r} / A_{u}$ & .75 \\
Relative technology level & $\sigma_{u}$ & .75 \\
U.S. openness & $\sigma_{r}$ & \\
ROW openness & & .396 \\
Without technology capital & $\phi$ & \\
Technology capital share & $A_{r} / A_{u}$ & \\
Relative technology level & & \\
\hline \hline
\end{tabular}


TABLE C.2. Initial Conditions for Transition Analysis in the Stripped-Down Model, Openness Parameters Fixed

\begin{tabular}{lcc}
\hline DESCRIPTION & ExPRESSION & VALUE \\
\hline With technology capital, $\phi>0$ & & \\
Tangible capital of Dell in U.S. & $K_{u 0}^{d}$ & 1.32 \\
Tangible capital of Fujitsu in U.S. & $K_{u 0}^{f}$ & .047 \\
Tangible capital of Dell in ROW & $K_{r 0}^{d}$ & .022 \\
Tangible capital of Fujitsu in ROW & $K_{r 0}^{f}$ & 2.89 \\
Technology capital of Dell & $M_{0}^{d}$ & .337 \\
Technology capital of Fujitsu & $M_{0}^{f}$ & .737 \\
Initial debt & & \\
No changes in exogenous variables & $B_{0}$ & 0 \\
ROW population as in Figure C.1 & $B_{0}$ & .047 \\
ROW TFP as in Figure C.2 & $B_{0}$ & .130 \\
Without technology capital, $\phi=0$ & & \\
Tangible capital of U.S. & & 1.60 \\
Tangible capital of ROW & $K_{u 0}$ & 3.42 \\
Initial debt & $K_{r 0}$ & \\
No changes in exogenous variables & & 0 \\
ROW population as in Figure C.1 & $B_{0}$ & -.081 \\
ROW TFP as in Figure C.2 & $B_{0}$ & .139 \\
\hline \hline
\end{tabular}


TABle C.3. Initial Conditions for Transition Analysis in the Stripped-Down Model, Openness Parameters Varying ${ }^{a}$

\begin{tabular}{lcc}
\hline DESCRIPTION & EXPRESSION & VALUE \\
\hline Tangible capital of Dell in U.S. & $K_{u 0}^{d}$ & 1.36 \\
Tangible capital of Fujitsu in U.S. & $K_{u 0}^{f}$ & .013 \\
Tangible capital of Dell in ROW & $K_{r 0}^{d}$ & .123 \\
Tangible capital of Fujitsu in ROW & $K_{r 0}^{f}$ & 2.79 \\
Technology capital of Dell & $M_{0}^{d}$ & .373 \\
Technology capital of Fujitsu & $M_{0}^{f}$ & .703 \\
Initial debt & $B_{0}$ & .047 \\
\hline \hline
\end{tabular}

${ }^{a}$ For this experiment, $\phi=.07, A_{r t}=.363$ for all $t$, the path $\left\{N_{r t}\right\}$ is shown in Figure C.1, and the paths for $\left\{\sigma_{i t}\right\}, i=u, r$ are shown in Figure C.11. 


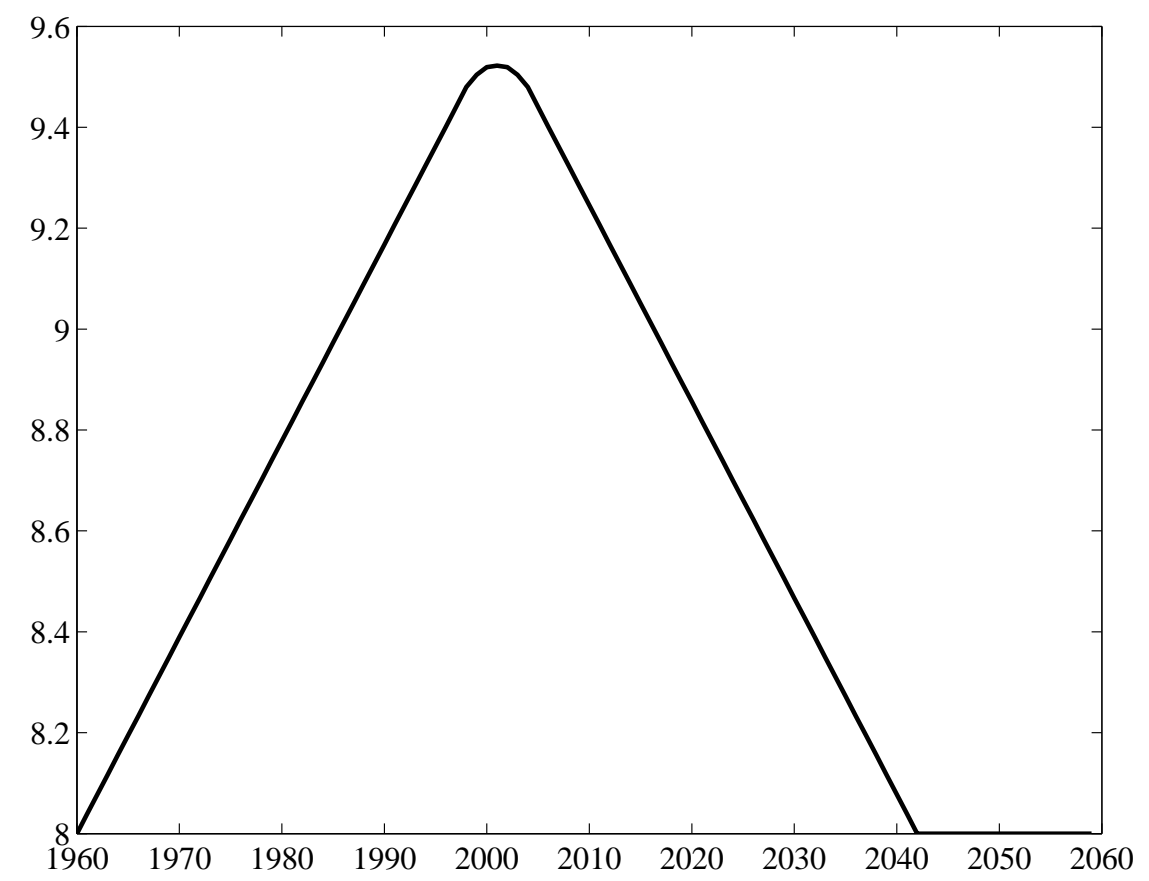

Figure C.1. Temporary Increase in ROW Population

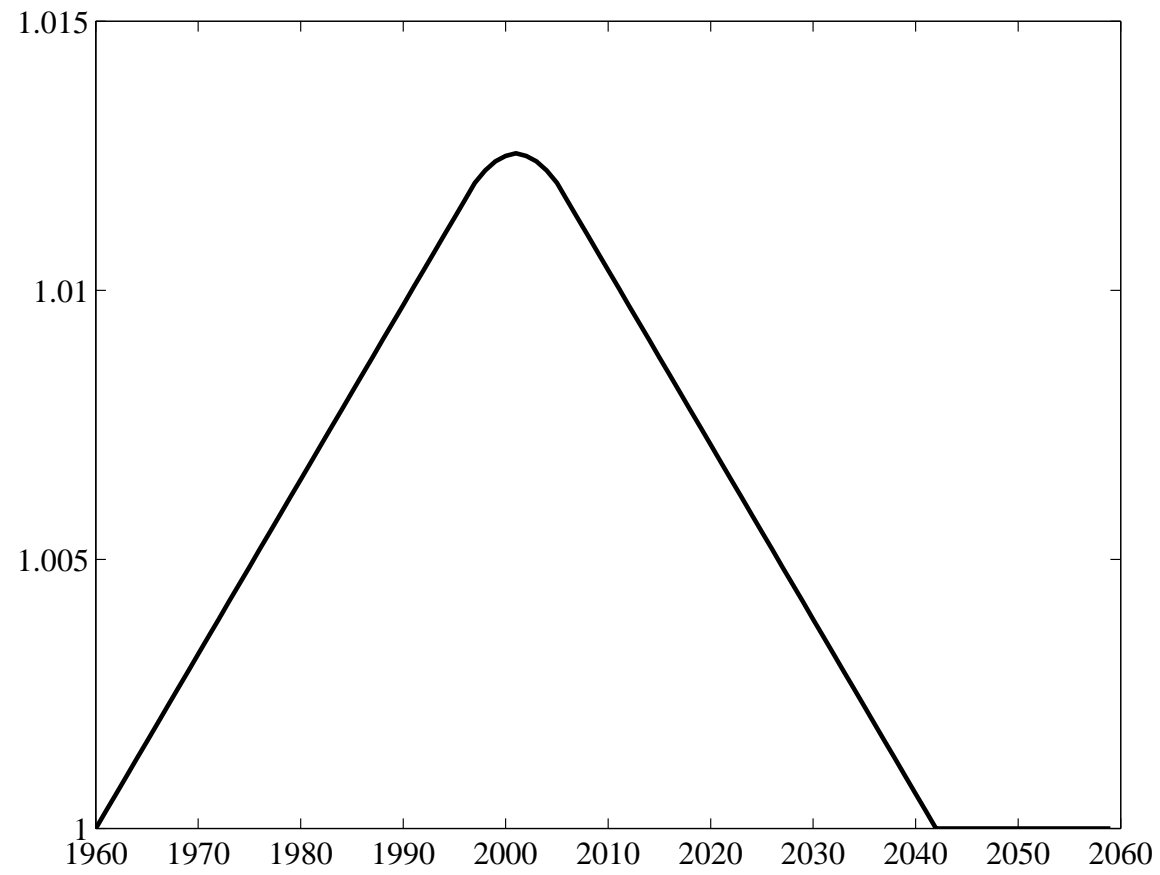

Figure C.2. Temporary Increase in ROW TFP 


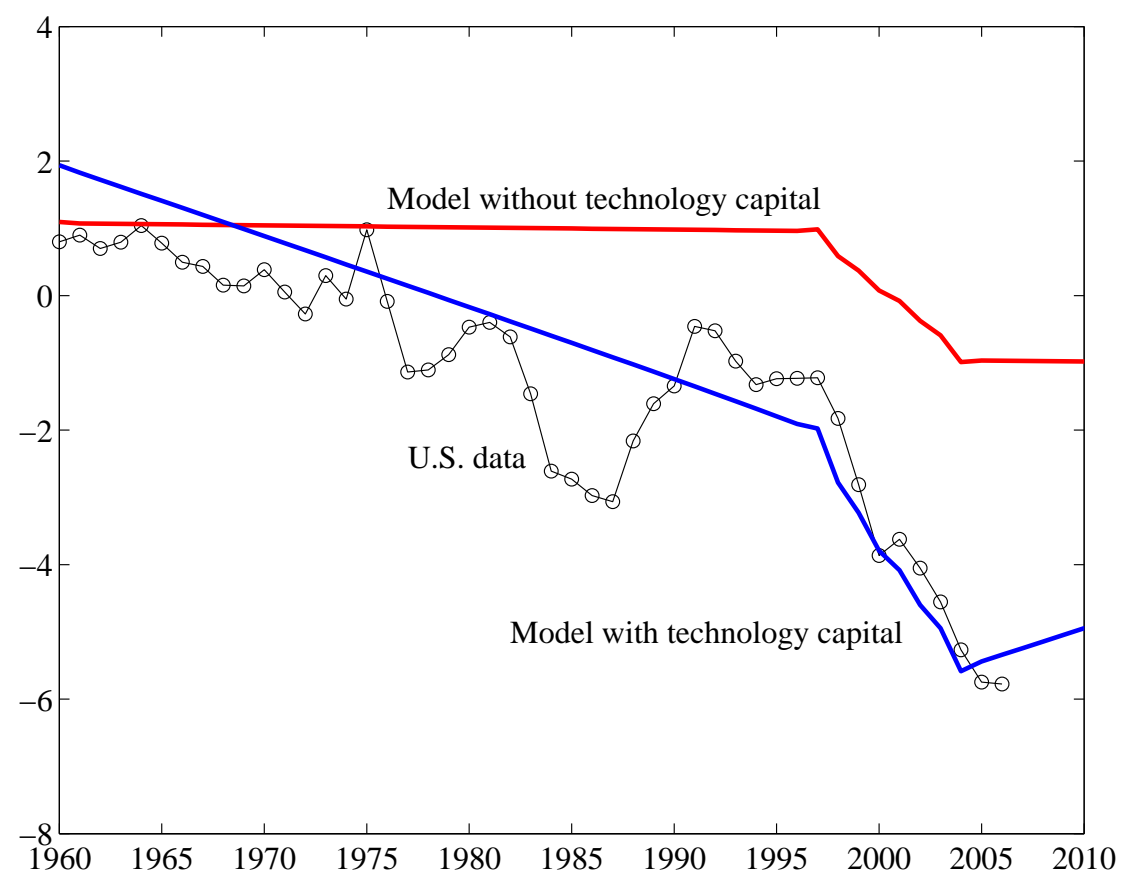

Figure C.3. U.S. Net Exports to GDP and Predictions in the StrippedDown Model with a Temporary Increase in ROW Population

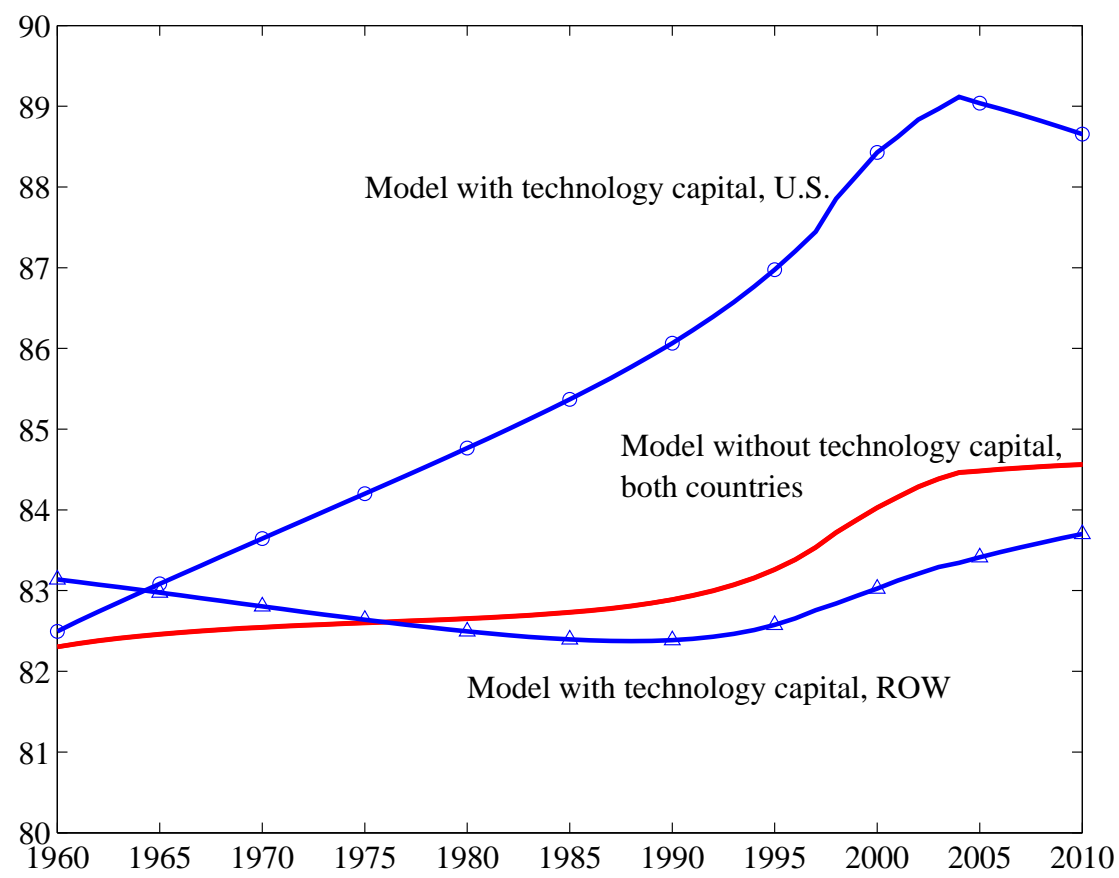

Figure C.4. Predictions of Consumption to GDP Ratio in the StrippedDown Model with a Temporary Increase in ROW Population 


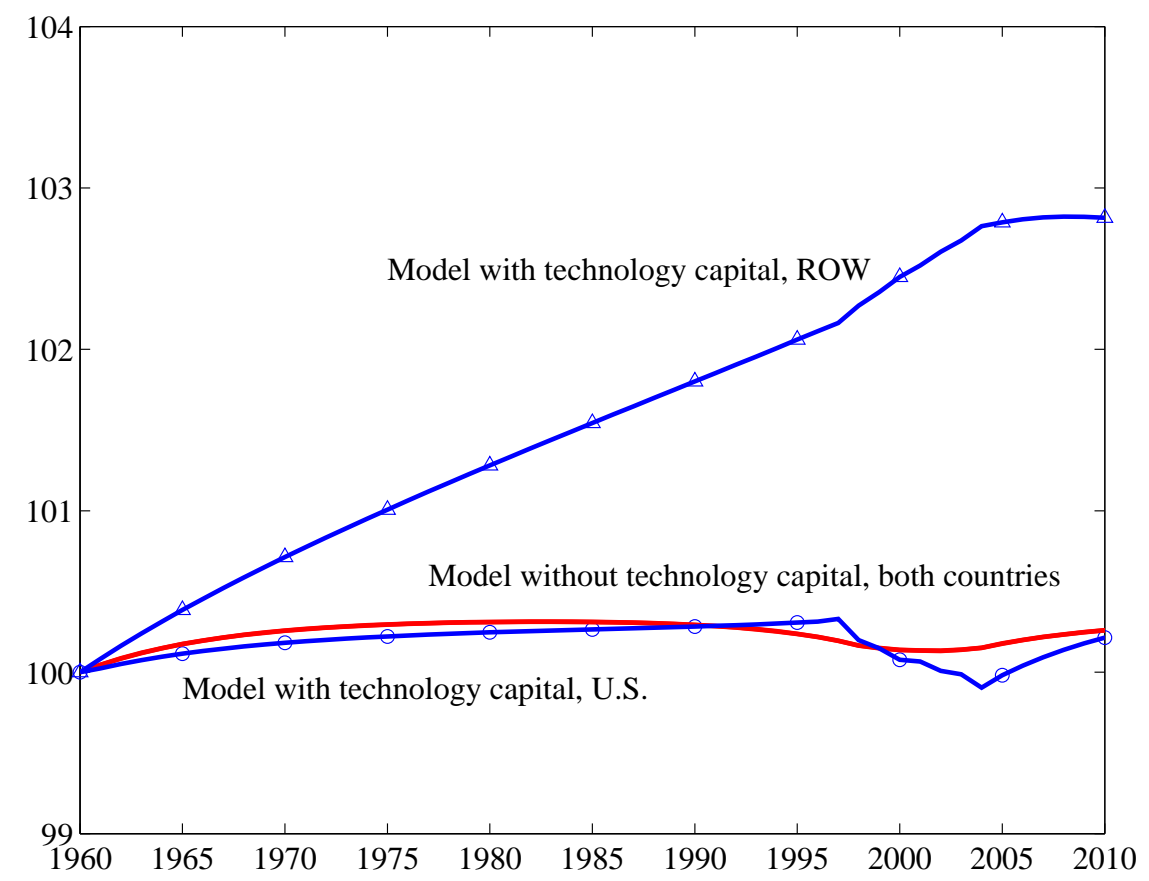

Figure C.5. Predictions of Labor Productivity in the StrippedDown Model with a Temporary Increase in ROW Population

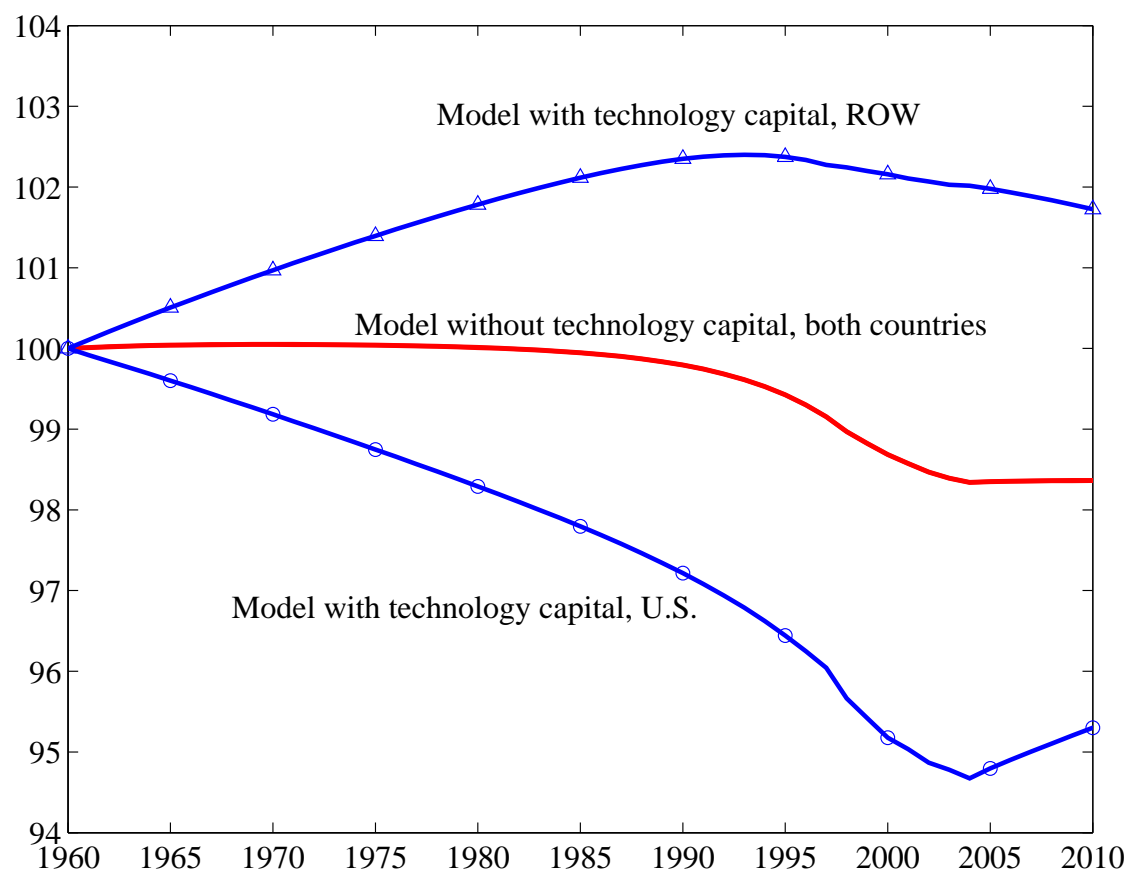

Figure C.6. Model Predictions of Per Capita GDP in the Stripped-

Down Model with a Temporary Increase in ROW Population 


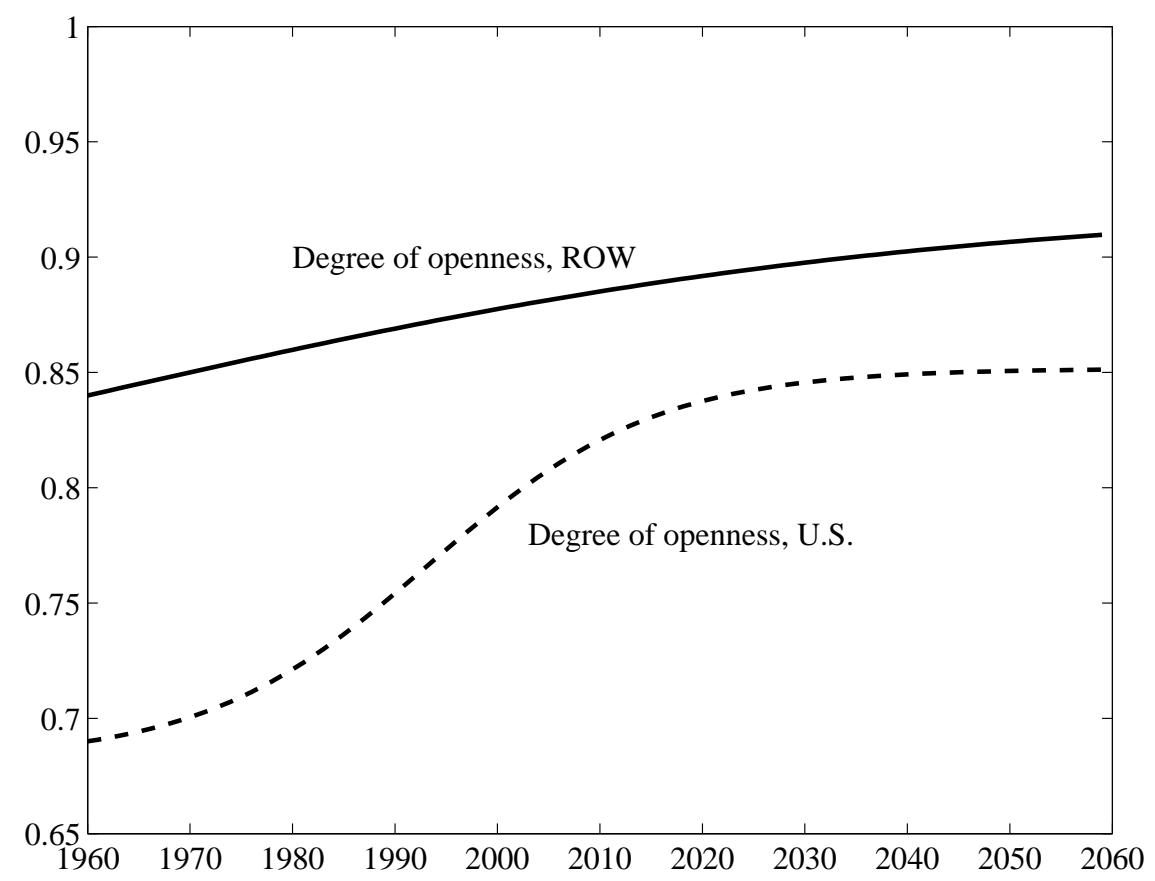

Figure C.7. Increasing Degrees of Openness

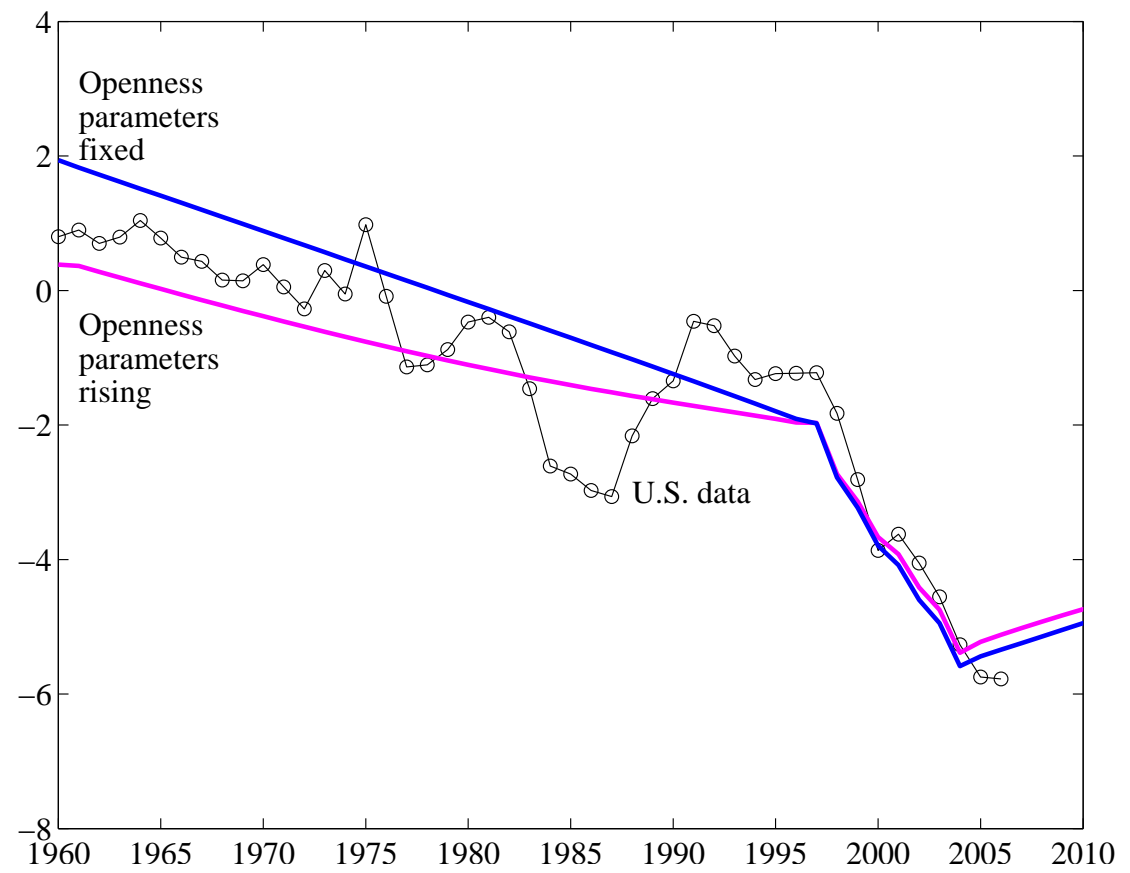

Figure C.8. U.S. Net Exports to GDP and Predictions in the Stripped-

Down Model with a Temporary Increase in ROW Population:

A Comparison of Fixed and Increasing Openness 


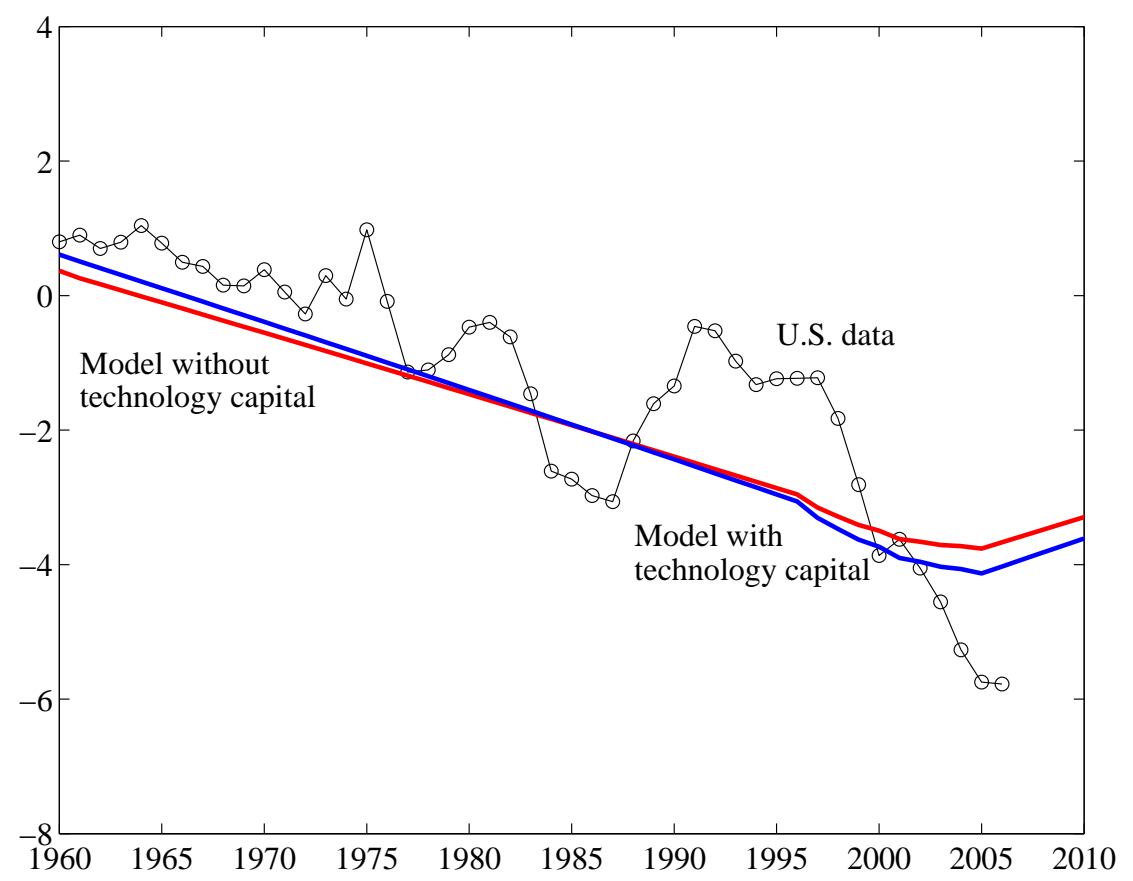

Figure C.9. U.S. Net Exports to GDP and Predictions in the StrippedDown Model with a Temporary Increase in ROW TFP

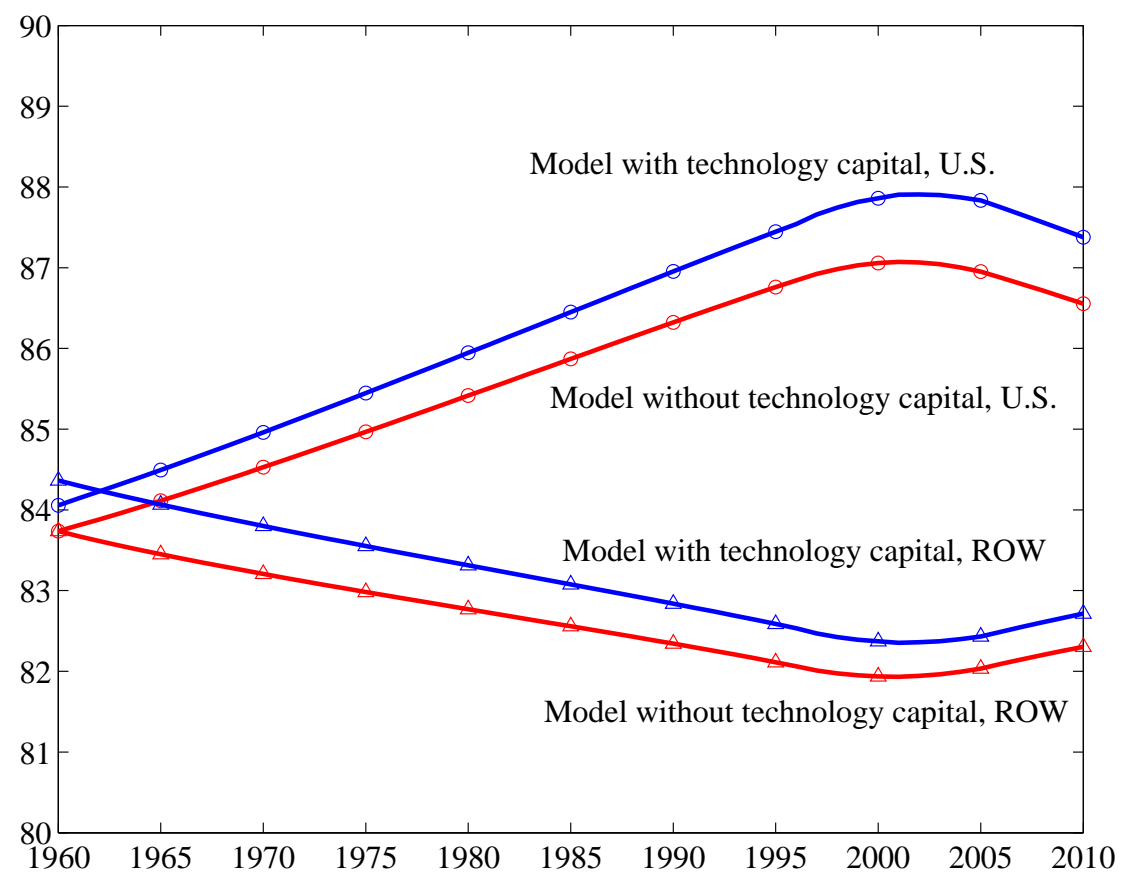

Figure C.10. Predictions of Consumption to GDP Ratio in the StrippedDown Model with a Temporary Increase in ROW TFP 


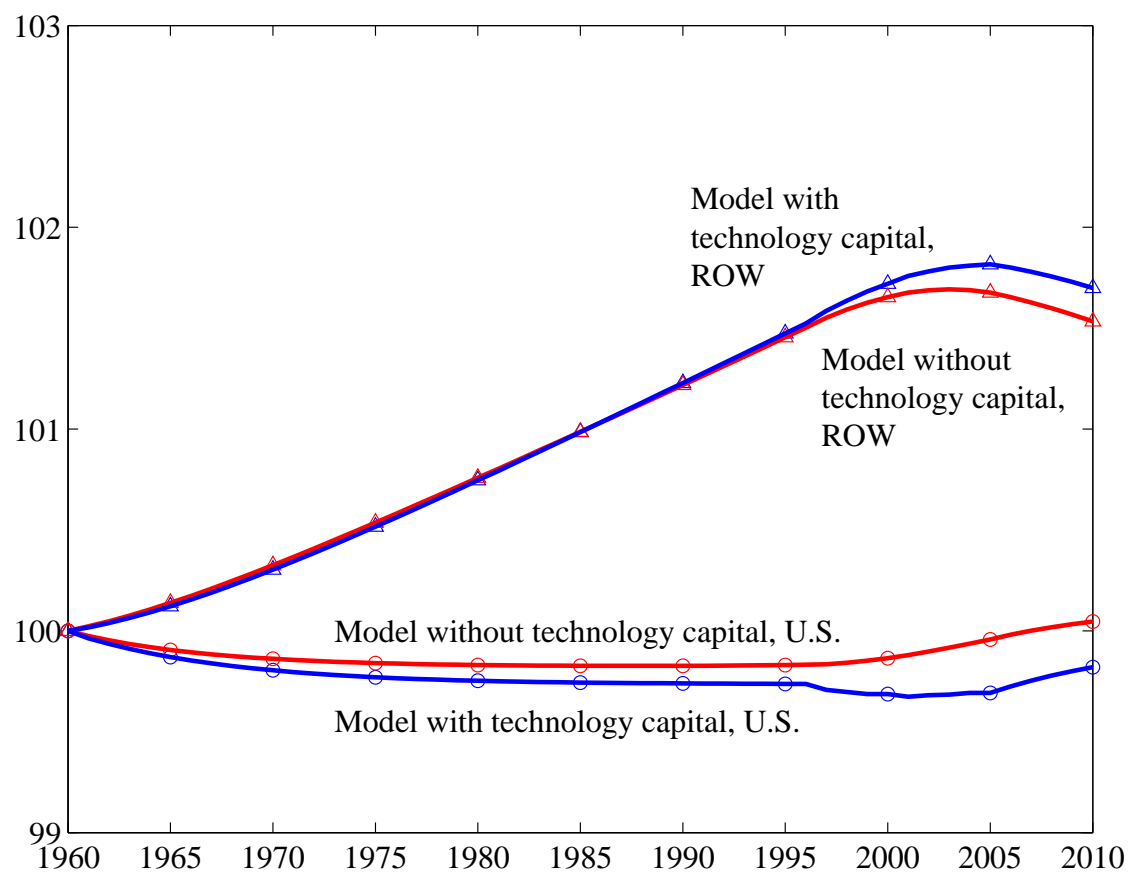

Figure C.11. Predictions of Labor Productivity in the StrippedDown Model with a Temporary Increase in ROW TFP

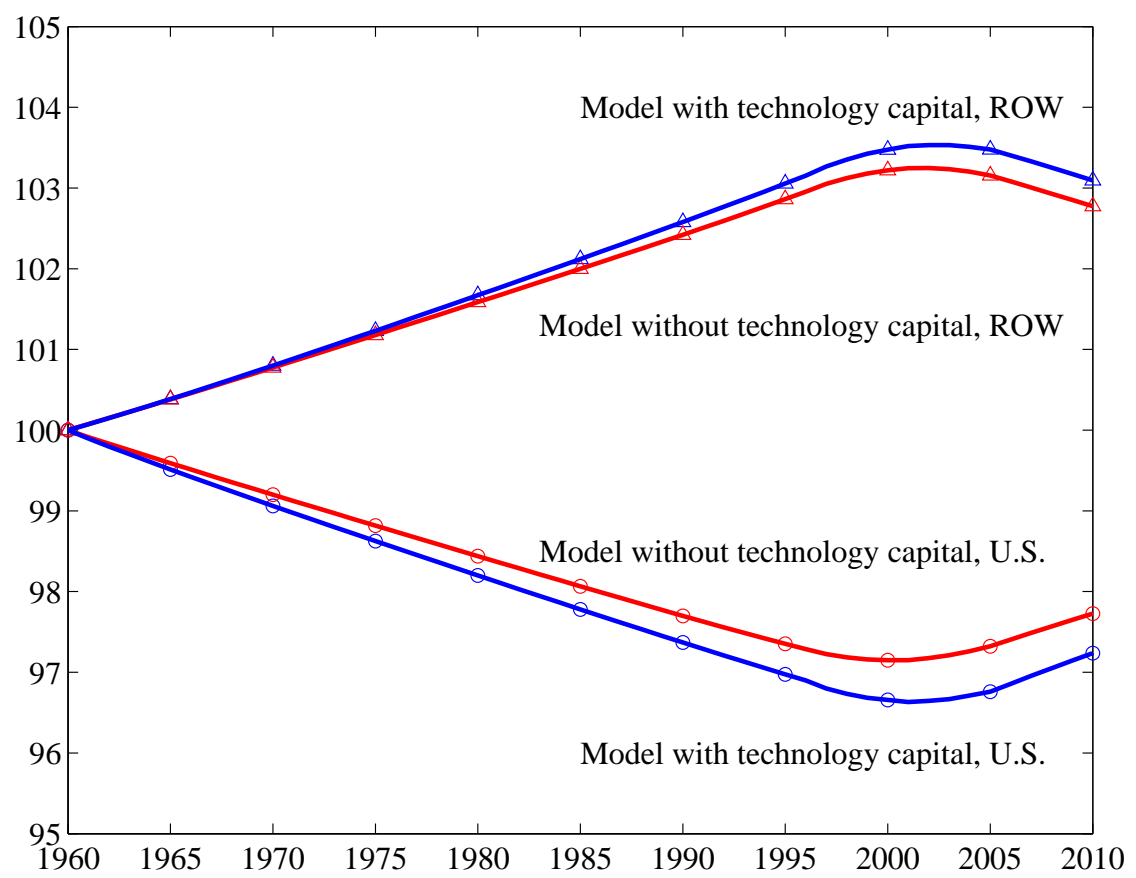

Figure C.12. Model Predictions of Per-Capita GDP in the StrippedDown Model With a Temporary Increase in ROW TFP 